Liu Shaozhuo (Orcid ID: 0000-0003-4833-5291)

Xu Xiwei (Orcid ID: 0000-0002-8301-7347)

Klinger Yann (Orcid ID: 0000-0003-2119-6391)

Nocquet Jean Mathieu (Orcid ID: 0000-0002-3436-9354)

Chen Guihua (Orcid ID: 0000-0001-8134-0194)

Jónsson Sigurjón (Orcid ID: 0000-0001-5378-7079)

\title{
Lower crustal heterogeneity beneath the northern Tibetan Plateau constrained by GPS measurements following the 2001 Mw7.8 Kokoxili earthquake
}

\section{Shaozhuo Liu ${ }^{1,3,5 \dagger}{ }^{\dagger}$ Xiwei $\mathrm{Xu}^{2}$, Yann Klinger ${ }^{3}$, Jean-Mathieu Nocquet ${ }^{3,4}$, Guihua Chen ${ }^{1}$, Guihua Yu${ }^{1}$, and Sigurjón Jónsson ${ }^{5}$}

${ }^{1}$ Key Laboratory of Active Tectonics and Volcano, Institute of Geology, China Earthquake Administration, Beijing 100029, China.

${ }^{2}$ Institute of Crustal Dynamics, China Earthquake Administration, Beijing, China.

${ }^{3}$ Université de Paris, Institut de physique du globe de Paris, CNRS, F-75005 Paris, France.

${ }^{4}$ Geoazur, IRD, Université Côte d'Azur, CNRS, Observatoire de la Côte d'Azur, Valbonne, France.

${ }^{5}$ King Abdullah University of Science and Technology, Thuwal, Saudi Arabia.

Correspondingauthor: Shaozhuo LIU (shaozhuoliu@gmail.com) and Xiwei Xu (xiweixu@vip.sina.com)

†now at King Abdullah University of Science and Technology

\section{Key Points:}

- Large asymmetric shear strain rate was found in the 2007-2015 post-Kokoxili 2001 earthquake GPS velocities;

- Postseismic transient deformation diffused away from the coseismic rupture through time;

- Modeling the geodetic data requires lower crustal heterogeneity in the northern Tibetan Plateau.

This article has been accepted for publication and undergone full peer review but has not been through the copyediting, typesetting, pagination and proofreading process which may lead to differences between this version and the Version of Record. Please cite this article as doi: 10.1029/2019JB017732 


\begin{abstract}
We use Global Positioning System (GPS) measurements across the Xidatan segment of the Kunlun fault in the Tibetan Plateau to investigate the surface deformation following the $2001 \mathrm{Mw} 7.8$ Kokoxili earthquake. We find significant post-seismic deformation during the period 2007-2015, characterized by an asymmetric shear across the 2001 rupture, with average velocities reaching $\sim 10 \mathrm{~mm} / \mathrm{yr}$ about $30-45 \mathrm{~km}$ south of the coseismic rupture. We also find that the postseismic transients diffused away from the coseismic rupture through time, with a shift of the maximum transient rates from $\sim 20-30 \mathrm{~km}$ south of the rupture in 2001-2002 to $\sim 30-45 \mathrm{~km}$ in 2007-2015. Viscoelastic relaxation is the dominant physical process during the period 2007-2015. The estimated effective viscosity of the lower crust beneath the Songpan-Ganzi terrane is $2 \times 10^{18}-3 \times 10^{18} \mathrm{~Pa}$ s from the $2001-2002$ data, and it has increased to $\sim 2 \times 10^{19} \mathrm{~Pa}$ s for the period 6 to 14 years after the event. The large asymmetry in the postseismic deformation field indicates a laterally heterogeneous lower crust beneath the northern Tibetan Plateau. Viscoelastic relaxation models show that the viscosity of the lower crust beneath the Qaidam basin is $\sim 2$ and $\sim 4$ times larger than the viscosity of the lower crust beneath the Songpan-Ganzi terrane in 2001-2002 and 2007-2015, respectively. Based on these data and results from previous studies, we postulate that the Kunlun fault itself is not the unique rheological boundary and that additional domains with viscosity increasing from the Qiangtang terrane to the Qaidam basin appear to be required.
\end{abstract}

\title{
Plain Language Summary
}

Viscoelastic relaxation of earthquake-induced deviatoric stress change can last for several decades. In 2001, the Mw7.8 Kokoxili earthquake occurred along the Kunlun fault in the northern Tibetan Plateau. GPS measurements in the first two decades after the 2001 event show (1) that postseismic transients diffused away from the fault and (2) that postseismic transients are asymmetric across the coseismic rupture. We find that lower crustal viscosity heterogeneity leads to the observed asymmetric deformation. Although geodetic data constraints with better spatial and temporal coverage are needed, we find that lower crustal viscosity may exhibit northward stepwise increase across the Jinsha River suture, Kunlun fault, and the southern margin of the Qaidam basin. Our findings provide new constraints on the lithospheric structure and tectonic deformation in the northern Tibetan Plateau.

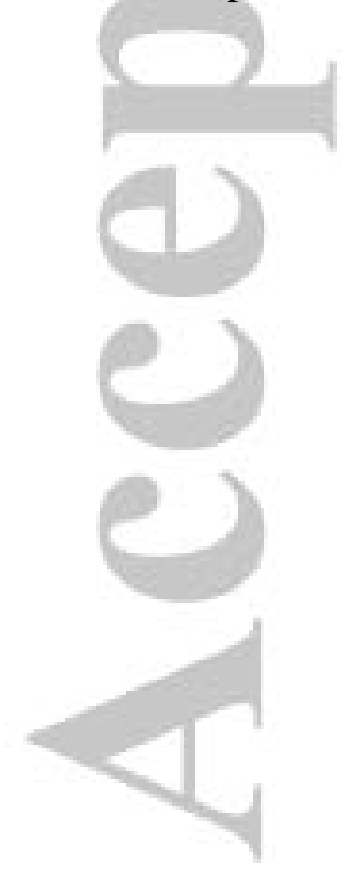




\section{Introduction}

1.1 Tectonic setting

The Kunlun fault (KLF) is a $1500-\mathrm{km}$-long left-lateral strike-slip fault in the northern Tibetan Plateau, accommodating the eastward escape of the plateau (Tapponnier et al., 2001; Yin \& Harrison, 2000). The KLF runs through the southern portion of the Kunlun Shan between the Songpan-Ganzi terrane to the south and the Qaidam Basin to the north (Figure 1). Its slip rate estimated from millennial-scale geomorphic offsets is roughly uniform at 10-12 $\mathrm{mm} / \mathrm{yr}$ along its central segment (longitude $94^{\circ} \mathrm{E}-101^{\circ} \mathrm{E}$ ) ( $\mathrm{Li}$ et al., 2005; Van der Woerd et al., 1998; Van Der Woerd et al., 2002), and it might decrease to less than $2 \mathrm{~mm} / \mathrm{yr}$ along its 150-km-long eastern tip (Kirby et al., 2007). Geodetic slip rates at the decadal time scale have been found either to be uniform within the range $6-15 \mathrm{~mm} / \mathrm{yr}$ along the central section (Chen et al., 2004; Loveless \& Meade, 2011; Meade, 2007; Thatcher, 2007; Wang et al., 2001) or to be distinctly exhibiting a linear, eastward decrease from $\sim 20 \mathrm{~mm} / \mathrm{yr}$ to a couple of millimeters per year (Gan et al., 2007; Zhang et al., 2013).

Most segments of the KLF ruptured through a series of $M>7$ earthquakes during the past 100 years (Figure 1), except the Xidatan-Dongdatan and Maqu segments (Wen et al., 2007). The most recent earthquake is the November $14^{\text {th }} 2001$ Mw7.8 Kokoxili event, which ruptured for over $\sim 420 \mathrm{~km}$ along the Kusai Lake segment of the Kunlun fault and the Kunlun Pass fault (longitude $90.2^{\circ} \mathrm{E}-94.8^{\circ} \mathrm{E}$ ) (Klinger et al., 2005; Xu et al., 2002), with peak offset reaching 7-8 $\mathrm{m}$ (Klinger et al., 2006; Xu et al., 2006). Other M>7 historical earthquakes include the 1937 Ms7.5 Tuosuo Lake earthquake, the 1963 Ms7.0 Alake Lake earthquakes, and the 1973 Ms7.3 and 1997 Mw7.6 Manyi earthquakes along the western splay of the KLF (Guo et al., 2007; Wen et al., 2007). The Xidatan-Dongdatan segment is therefore considered as a seismic gap.

\subsection{Previous studies of the regional lithospheric structure}

How we interpret the patterns of lithospheric deformation within and around the Tibetan Plateau depends to some extent on where the strength resides in the lithosphere. One of the representative models proposed so far to explain the large-scale topography and growth of the Tibetan Plateau is the so-called "channel flow" model, in which a relatively weak (long-term viscosity potentially lower than $1 \times 10^{18}$ Pas) middle and lower crust is decoupled from the elastic upper crust and the underlying strong viscoelastic upper mantle (Beaumont et al., 2001; Clark \& Royden, 2000; Royden et al., 1997).

Some geophysical studies lend support to the crustal "channel flow" model for the northern Tibetan Plateau because some geophysical observations, such as high conductivity from magnetotelluric studies (Bai et al., 2010; Unsworth et al., 2004; Wei et al., 2001), high seismic attenuation (Fan \& Lay, 2002; Rodgers \& Schwartz, 1998), and seismic anisotropy (Shapiro et al., 2004), were interpreted as evidence that channel(s) of partial melt exists in the middle and lower crust. However, the physics relating electrical conductivity and seismic attenuation to the strength (viscosity) is not well understood, and thus an alternative interpretation that does not rely on the presence of widespread partial melt has also been proposed (Vergne et al., 2002).

However, most geodetic studies on earthquake-cycle deformation along the KLF constrained by GPS/InSAR measurements do not fully support the lower crustal "channel flow" model (e.g., Clark \& Royden, 2000; Royden et al., 1997). Those geodetic studies provide 
independent constraints on the rheological properties of the lithosphere in this region. Those studies can be categorized into two groups according to the time span of interest and how the data are interpreted: (1) modeling postseismic deformation that relies on postseismic observations several years/decades after an earthquake (Diao et al., 2011; He et al., 2018; Ryder et al., 2011; Shao et al., 2008; Wen et al., 2012) and (2) modeling earthquake-cycle deformation in which geodetic observations, at any stage of the earthquake cycle, result both from interseismic strain accumulation and postseismic relaxation (DeVries \& Meade, 2013; Hilley et al., 2005; Hilley et al., 2009). Depending on the model settings and data constraints, the estimated effective viscosities of the viscoelastic medium vary, but they are typically larger than $10^{18} \mathrm{~Pa} \mathrm{~s}$, with the preferred values around $1-2 \times 10^{19} \mathrm{~Pa} \mathrm{~s}$. These findings are not consistent with the preferred lower crustal viscosity for the central Tibetan Plateau in the "channel flow" model (e.g., Clark \& Royden, 2000; Royden et al., 1997).

Meanwhile, some geophysical studies reveal lithospheric heterogeneity in the northern Tibetan Plateau. Previous magnetotelluric and seismological studies highlighted lithospheric structure contrasts from the Songpan-Ganzi terrane, south of the KLF, to the Qaidam Basin, north of the KLF. These studies suggest that the crust may exhibit a sharp $\sim 10-20 \mathrm{~km}$ thinning from the Songpan-Ganzi terrane to the Qaidam Basin (Karplus et al., 2011; Zhu \& Helmberger, 1998). The lithospheric structure contrast is also indicated by a mechanical heterogeneity, which include higher Poisson's ratio (Owens \& Zandt, 1997), higher conductivity (Unsworth et al., 2004; Wei et al., 2001), and lower seismic velocities (Yang et al., 2012) in the lower crust beneath the Songpan-Ganzi terrane.

However, where the heterogeneity occurs remains unclear. The KLF itself may be a major rheological boundary because pervasive middle and lower crustal conductors may abruptly terminate beneath the Songpan-Ganzi terrane (Unsworth et al., 2004) and a major pocket of low shear-wave velocity may be present in the middle crust (Yang et al., 2012) just south of the KLF. On the other hand, most geological and geophysical studies put the heterogeneity boundary somewhere north of the KLF (along the southern margin of the Qaidam Basin), but then we cannot specifically identify the associated geologic structures. For example, Moho offset (Karplus et al., 2011; Zhu \& Helmberger, 1998), south- (Yin et al., 2007) or northvergent (Meyer et al., 1998) crustal thrust faults are possible candidates. Furthermore, the lithospheric structure across the KLF may exhibit second order complexities. For example, a rheological transition zone may be present between the KLF and the Qaidam Basin (Le Pape et al., 2012).

\subsection{Motivation of this study}

If the main boundary for the mechanical properties of the lithosphere is located along the $\mathrm{KLF}$, asymmetric deformation is expected to be observed across the KLF. During the preKokoxili earthquake period, however, no asymmetric deformation pattern could be observed with the sparse GPS observations (Wang et al., 2003b; Zhang et al., 2004). Similarly, asymmetric coseismic deformation is not significant because GPS- and InSAR-derived coseismic deformation fields only showed minor differences in the peak deformation between the two sides of the rupture (Lasserre et al., 2005; Ren \& Wang, 2005), with a maximum of $10 \%$ to $20 \%$ larger displacement on the southern side compared to the northern side (Lasserre et al., 2005; Wan et al., 2008). Conversely, postseismic GPS and InSAR (Zhao et al., 2018) observations exhibit remarkable asymmetry: in the first year, the ratio of asymmetry is $\sim 2$, and it increases to more than 3 during the following years (see section 3 ). 
If all the pre-Kokoxili, coseismic, and postseismic geodetic observations do show asymmetric deformation, modeling all the data would enable us to investigate the mechanical heterogeneity at lithospheric scale. Indeed, interseismic deformation is sensitive to mechanical properties of the upper elastic layer and perhaps the underlying platosphere; coseismic deformation is sensitive to elastic structure of the crust; postseismic deformation is sensitive to viscoelastic properties of the lower crust and upper mantle. Because the crust beneath the northern Tibetan Plateau is rather thick and (because) the earthquake-induced deviatoric stress change in most sections of the uppermost mantle may be too low to drive active postseismic viscoelastic flow, post-Kokoxili GPS data probably reflect only postseismic physical processes above a certain depth (not significantly deeper than the Moho depth).

In this study, we present a new data set consisting of 10 continuous GPS (cGPS) sites (at most) located along a $\sim 320-\mathrm{km}$-long profile obliquely crossing the Xidatan segment of the KLF (longitude $\sim 94^{\circ} \mathrm{E}$, Figures 1 and 2). Our cGPS network, progressively installed since 2007, complements previous 2003-2010 InSAR measurements (Ryder et al., 2011; Wen et al., 2012; Zhao et al., 2018) and 2001-2007 GPS (He et al., 2018; Ren \& Wang, 2005), thus enabling us to quantify the slower, "more steady" part of the postseismic phase. Based on the asymmetric pattern as seen in the post-Kokoxili GPS measurements, we thoroughly explore the effects of lower crustal heterogeneity on the postseismic deformation, which has not been addressed well in previous geodetic studies.

The following conventions are used in this study. We refer to "secular velocities" as the preearthquake velocities that describe the steady motion late in the seismic cycle. The steady motion and postseismic transients in the post-earthquake GPS position time series can be characterized by linear and logarithmic/exponential functions, respectively. The best-fit linear rates - the "nominally interseismic velocities"-are not always the secular velocities but may include residual short-term and/or long-term postseismic transients (Liu et al., 2015). For the post-earthquake observations exhibiting quasi-steady motion (e.g., our Xidatan observations), linear function provides a good fit to the observations, and the best-fit velocities are a sum of secular velocities and postseismic transients (equivalent to the residual postseismic transients in the nominally interseismic velocities, see section 2.3 ).

This paper is organized as follows: We first present the GPS data, showing that significant post-seismic deformation was still occurring during the period 2007-2015, and we then describe their main characteristics (section 2). We follow this by discussing how the preKokoxili deformation models can be used to extract the postseismic transients in the velocities averaged over the period 2007-2015 (section 3), showing that (1) postseismic transients reach a maximum of $\sim 10 \mathrm{~mm} / \mathrm{yr}$, at $\sim 30-45 \mathrm{~km}$ south from the KLF and (2) postseismic transients are at least three times larger south of the KLF than to the north of the KLF. In section 4, we focus on modeling the observed deformation pattern, and we show that lateral variations of rheological properties of the lower crust from the Qiangtang and Songpan-Ganzi terranes to the Qaidam basin are required to explain the geodetic observations. Finally, we compare our results with GPS- and InSAR-based models and discuss the implications of our results for the rheology of the northern Tibetan Plateau.

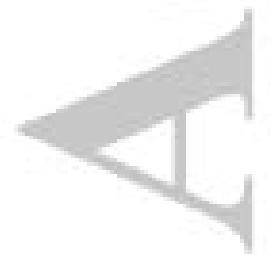




\section{Data}

2.1 XidatancGPS data

We use the GAMIT/GLOBK software 10.6 release (Herring et al., 2015) to analyze the cGPS data from our network (hereafter referred as the XDT network), together with cGPS data of 16 sites from the Crustal Movement Observation Network of China (CMONOC) and 42 sites from the International GNSS Service (IGS, http://www.igs.org) GPS sites (Figure S1). The GPS position time series are first expressed in the International Terrestrial Reference Frame 2008 (ITRF2008, (Altamimi et al., 2011)). In a second step, to improve the quality of the time series, we remove outliers, correct for offsets, and remove the regional common mode errors (Text S1 in the supporting information). Finally, "realistic" velocity uncertainties are estimated using the method of Langbein (2017) that accounts for time-correlated noise.

Shown in Figure 2 are the position time series relative to the Qaidam Basin. For most sites, the position time series spanning 2007-2015 exhibit seasonal signals fluctuating around the quasi-steady motion at constant velocity. However, subtle decay of velocity through time can be observed at sites DUOX and YZSE located within $\sim 70 \mathrm{~km}$ south away from the Kunlun Pass fault (Text S1 in the supporting information). For instance, the one-year cumulative east-directed displacement at site DUOX decreases by 4-5 mm from 2008-2009 to 20132014. Nonetheless, given the overall small amplitude of velocity change through time, we will use constant best-fit velocities to the 2007-2015 position time series for subsequent analysis and discussion.

The derived nominally interseismic velocities are further aligned into the same reference frame as the pre-Kokoxili CMONOC-I GPS velocities (Table 1, relative to stable Eurasia) by minimizing the postfit velocity residuals at co-located GPS sites away from the area of postseismic deformation within and around the Tibetan Plateau (Text S1 in the supporting information).

\subsection{Other GPS data}

In addition to our XDT cGPS data (Table 2), we also use published velocities from CMONOC-I/II GPS campaigns (Wang et al., 2003b; Zhang et al., 2004; Zheng et al., 2017) and the post-Kokoxili GPS displacements (Ren \& Wang, 2005) at sites lying along the Qingzang Road (west of our XDT profile).

The CMONOC-I GPS velocities used in this study were derived from pre-Kokoxili GPS observations only, which were collected two or three times per year since the 1990s (Wang et al., 2003b). Although sparse, these data provide key constraints on decadal time scale interseismic (pre-Kokoxili) deformation field in the northern Tibetan Plateau. We will use this dataset to extract the postseismic transients in the section 3. GPS velocities averaged over 2009-2015 at the CMONOC-II sites (Zheng et al., 2017) roughly cover the same observation period as our XDT network and are used in our discussion to improve the spatial coverage.

The post-Kokoxili GPS observations along the Qingzang Road (hereafter called QZ profile) captured the early rapid postseismic transients during the first year after the earthquake (December 2001-November 2002, (Ren \& Wang, 2005)). Postseismic transients along QZ and XDT profiles, as well as in the CMONOC-II GPS velocities, are used to constrain postseismic physical processes associated with the 2001 event. 


\subsection{Analysis of GPS results}

2.3.1 Abnormal "pulse" in the fault-parallel post-2001.9 GPS velocities

To get a first sense of the deformation signal included in the 2007-2015 velocities, we show pre-Kokoxili CMONOC-I GPS velocities, 2009-2015 CMONOC-II campaign GPS and 20072015 XDT cGPS velocities on the same plot (Figure 3); we show the corresponding faultparallel and fault-perpendicular components in Figure 4. For both figures, we expressed the pre- and post-Kokoxili GPS velocities in a reference frame corresponding to the stable Qaidam basin (Text S1 in the supporting information). Because pre- and post-Kokoxili earthquake velocities agree within uncertainties in the far field (>150 km from the KLF), we can exclude any bias greater than 1-2 mm/yr coming from reference misalignment. Furthermore, as expected from their observation periods, we see a good consistency between the 2009-2015 CMONOC-II GPS and our 2007-2015 XDT GPS solutions.

South of the KLF, over $200 \mathrm{~km}$, the post-Kokoxili fault-parallel GPS velocity profile (20072015 XDT and 2009-2015 CMONOC-II) exhibits a convex shape (Figure 4). Within $20 \mathrm{~km}$ of the fault, the fault-parallel velocities are $\sim 15 \mathrm{~mm} / \mathrm{yr}$. About $30-45 \mathrm{~km}$ south from the KLF, the fault-parallel velocities peak at $\sim 20 \mathrm{~mm} / \mathrm{yr}$, and then gradually decrease to an asymptotic value of $10-13 \mathrm{~mm} / \mathrm{yr}$ farther south. The pattern of post-Kokoxili fault-parallel velocities observed north of the KLF is drastically different: no obvious concave shape is observed, and the differential velocity is less than $6 \mathrm{~mm} / \mathrm{yr}$.

Unlike the 2007-2015 velocities, the pre-Kokoxili velocity profile (CMONOC-I GPS) shows an arctangent shape across the KLF, as classically observed for a locked strike-slip fault (Savage \& Burford, 1973). No obvious asymmetry can be observed, unlike in the postseismic velocities.

The differential fault-parallel velocities (2007/2009-2015 CMONOC-II/XDT minus 19942001 CMONOC-I) resemble a pulse of accelerated velocities localized within $\sim 200 \mathrm{~km}$ south of the fault, where velocity increases by several to ten millimeters per year, and then decreases to zero farther away from the fault. In the northern side, the lack of pre-Kokoxili velocities precludes any reliable comparison directly from the data.

A standard interseismic dislocation model alone, with deep creep rate set at the far-field velocity below a certain locking depth, is not able to explain the observed pattern of postKokoxili fault-parallel GPS velocities. The abnormal "pulse" of high velocities south of the KLF suggests that additional processes occurring below the upper crust are required to produce the observed excess of velocities within $150 \mathrm{~km}$ from the fault.

2.3.2 Does the 2007-2015 GPS velocity field reflect a new interseismic state 6 years after the Kokoxili earthquake?

Here, we test the possibility that the 2007-2015 GPS velocities represent a new interseismic steady state, rather than transient postseismic deformation. First, we use a standard screw dislocation model (Savage \& Burford, 1973) to fit the 2007-2015 GPS velocities north of the Ganzi-Yushu fault. The high velocities and the sharp gradient across the KLF require slip rate largely exceeding $10 \mathrm{~mm} / \mathrm{yr}$ and shallow locking depth. Taking the Kusai Lake segment as the main fault, this approach yields a slip rate of $15.6 \pm 1.5 \mathrm{~mm} / \mathrm{yr}$ and a locking depth of $6.9 \pm 2.0 \mathrm{~km}$ (see Text S2, Figures S5a and S5b). Alternatively, taking the Xidatan segment as the main fault, we find a slip rate of $13.4 \pm 1.1 \mathrm{~mm} / \mathrm{yr}$ and almost full creep (locking depth of 
$0.6 \pm 0.8)$. These slip rates are several millimeters larger than the geologic long-term slip rate (Van Der Woerd et al., 2002), and are also significantly faster than the pre-Kokoxili far-field loading rate (Figure 5a, Text S2 in the supporting information).

We also test the possibility that the Xidatan segment of the KLF, which did not rupture during the 2001 Kokoxili earthquake, might be creeping during the period 2007-2015. We find that the stress increment on the Xidatan segment due to the 2001 rupture (Figure S7) is negative for left-lateral slip on the shallowest $15 \mathrm{~km}$ of the fault. Thus, triggered postearthquake shallow creep is unlikely (Text S3 in the supporting information). We find a similar conclusion for shallow creep occurring along the Kusai Lake segment (Figure S8).

Because the standard screw dislocation model is unable to explain the asymmetric pattern observed in the 2007-2015 GPS velocity profile, we also test the effect of elastic heterogeneity across the KLF fault in our model, using the method proposed in Lisowski et al. (1991) (Text S3 in the supporting information). For a locking depth of $15 \mathrm{~km}$, the shear modulus across the fault (from the Songpan-Ganzi terrane to the Qaidam Basin) would need to increase at least ten folds (Figure 5b), which is an unrealistically large difference for this region (Yang et al., 2012). For a locking depth of $\sim 6.0 \mathrm{~km}$, the elastic heterogeneity required is closer to a possible contrast, around one (Figure 5a), and it can explain the observed gradient. However, this does not correctly predict the velocity $100 \mathrm{~km}$ away from the fault. Thus, these tests indicate that elastic heterogeneity in the crust is not the main causative factor in explaining the sharp strain rate gradient immediately adjacent to the fault after the 2001 event.

Furthermore, assuming that the period 2007-2015 already corresponds to a new interseismic state would imply that postseismic deformation lasted only during the first few years after the earthquake. If it would be the case, postseismic relaxation signals would be almost zero in the period 2007-2015 (section 3.4), and the effective viscosity of the lower crust would be greater than $1.0 \times 10^{20} \mathrm{~Pa} \mathrm{~s}\left(1.0 \times 10^{21} \mathrm{~Pa} \mathrm{~s}\right.$ is also acceptable $)$. That means that the effective viscosity of the lower crust increased by more than two orders in the first decade after the 2001 event, which is inconsistent with postseismic deformation modeling results for large strike-slip earthquakes elsewhere in the world (e.g., Bürgmann \& Dresen, 2008).

Therefore, the hypothesis of a new interseismic state in the period 2007-2015 does not hold, and a portion of the 2007-2015 XDT GPS velocities describe the slower "more steady" postseismic deformation.

\subsubsection{Nature of the anomalies in the post-2001.9 GPS velocities}

Postseismic transients of the 2001 event are characterized by exponential decay with rapid change in the first few years and gradual change afterward (He et al., 2018; Ren \& Wang, 2005). Without evidence from direct measurements, little is known about how long the postseismic transients could last. For some historical earthquakes, such as the 1906 Mw7.9 San Francisco earthquake (Kenner \& Segall, 2000), postseismic transients are strong in the geodetic measurements during the first few decades, and may have lasted for a century. For the Kokoxili earthquake, postseismic transients may have been captured by the CMONOC-II and Xidatan GPS observations, because GPS data were collected near the eastern end of the 2001 rupture during the first and second decades after the 2001 event. However, because the postseismic transients during this period appear to be at constant velocities, it is impossible to discriminate the secular deformation from postseismic transients in the GPS position time series, using classical GPS time series analysis alone, as it has been shown in the Mojave 
shear zone (Liu et al., 2015; Savage \& Svarc, 2009). If postseismic viscoelastic relaxation in a "weaker" lower crust (or even upper mantle) beneath the Songpan-Ganzi terrane would be more efficient than in the northern side of the KLF, it would not be surprising to find localized and asymmetric left-lateral shear in excess of the pre-Kokoxili deformation, as shown schematically by the green vectors in Figure 5c.

\section{Extracting the postseismic transients}

To be used as input data for subsequent modeling, we need to express our 2007-2015 velocities with respect to the pre-Kokoxili interseismic state. Of course, when available, the best way to obtain secular velocities is to directly estimate the linear trends from preearthquake observations. However, because GPS measurements across the KLF were mostly collected after the 2001 event, instead we had to use several pre-Kokoxili deformation models constrained by pre-Kokoxili CMONOC-I GPS velocities to attempt to recover secular velocities at the post-Kokoxili GPS sites. To obtain a reference result, we first present the residual postseismic transients (RPT) in the nominally interseismic GPS velocities at the GPS sites with both pre- and post-Kokoxili data.

\subsection{Postseismic signal from 1999-2014 campaign sites}

The benchmark RPT are defined as the excess of the nominally interseismic GPS velocities derived from post-Kokoxili observations relative to pre-Kokoxili velocities derived from preKokoxili observations. The nominally interseismic velocity of each component on each station is characterized by the $v_{l}$ in the formula $y_{l}(t)=a_{1}+v_{l} \times t+p \times \log \left(1+\left(t-t_{0}\right) / \tau\right)$, in which the position $y_{l}$ at time $t$ after the 2001 event is a function of linear trend at rate $v_{l}$ and nonlinear postseismic transients characterized by the logarithmic function with relaxation time, $\tau$, and $t_{0}$ is the time of the earthquake. The pre-Kokoxili velocity is the slope in the pre-Kokoxili GPS position time series ( $v_{2}$ in the formula $y_{2}(t)=a_{2}+v_{2} \times t$, in which $y_{2}(t)$ are the pre-Kokoxili positions).

Near the KLF, GPS measurements at JB30 and JB51 (Figure S9) are available for the period 1999.3-2014 (Text S4 in the supporting information). Although a 2.5-years period before the November 2001 Kokoxili earthquake is short to get an accurate estimate of velocity from 3 to 4 surveys, these data remain useful to evaluate the change observed after 2001.

We find that JB51 shows $\sim 5 \pm 1.6 \mathrm{~mm} / \mathrm{yr} \mathrm{S} 78 \pm 12^{\circ} \mathrm{E}$-directed motion relative to its pre-2001 velocity (Figure 6). However, for the JB30, no clear change is found $(\sim 0.7 \pm 2.7 \mathrm{~mm} / \mathrm{yr}$ $\mathrm{N} 56 \pm 153^{\circ} \mathrm{W}$-directed motion at JB30). Because JB30 and JB51 are on the opposite side of and at about the same distance from the fault, these results provide a direct observation of the asymmetric post-seismic deformation (asymmetric left-lateral shear parallel to the 2001 rupture).

\subsection{Pre-Kokoxili earthquake deformation models}

The patterns of contemporary crustal deformation of the northern Tibetan Plateau are rather complex, because of the presence of block rotation, fault-locking effects (Meade, 2007; Thatcher, 2007), coseismic and postseismic transients of recent earthquakes (Ren \& Wang, 2005; Ryder et al., 2011), and distributed strain (Loveless \& Meade, 2011; Zhang et al., 2013). Nonetheless, the pre-Kokoxili strain-rate field should be continuous within the long and thin area in which both the pre- and post-Kokoxili GPS observations were collected. Given the limited number of pre-Kokoxili geodetic data and the complex deformation field, we have developed several alternative approaches to predict secular velocities at the post- 
Kokoxili GPS sites, and we discuss the pros and cons of these different approaches to estimate post-seismic transients.

\subsubsection{D dislocation models}

In our 2D models, we use two buried screw dislocations to model strain accumulation on two regional active faults, one representing the Kunlun fault and the other one striking $\mathrm{S} 73^{\circ} \mathrm{E}$ representing the Fenghuoshan segment of the Ganzi-Yushu fault. Other active faults in this region are not included, because the effects of elastic strain accumulation from those faults on our GPS velocities are minor (Text S5.1 in the supporting information). Since our data were collected along a profile crossing two sections of the Kunlun fault with slightly different strikes, we first assessed the effect of specifying strike of the screw dislocation on the modeling results (Text S5.2 in the supporting information).

In the 2D models, fault-parallel velocities, $v$, result from the strain accumulation of the two faults incorporated, which can be described mathematically as

$$
v=v_{0}+\frac{s_{1}}{\pi} \tan ^{-1}\left(\frac{x_{1}}{d_{1}}\right)+\frac{s_{2}}{\pi} \tan ^{-1}\left(\frac{x_{2}}{d_{2}}\right) \cos (\delta)
$$

in which $s_{1}$ and $s_{2}$ are the slip rates on the Kunlun and Ganzi-Yushu faults, respectively; $d_{1}$ and $d_{2}$ are the locking depths of the two faults; $v_{0}$ is used to translate the modeled velocities into the reference frame of the observed velocities (far-field zero velocity); $x_{1}$ and $x_{2}$ are the distances from the GPS sites to the two fault segments; and $\delta$ accounts for the misalignment of the fault strikes. We use Monte Carlo simulation to explore potential uncertainties in the modeling results (Text S5.1 in the supporting information). We examine locking depths ( $d_{1}$ and $\left.d_{2}\right)$ between $5.0 \mathrm{~km}$ and $20.0 \mathrm{~km}$, and cumulative slip rate $\left(s_{1}+s_{2}\right)$ between $8.0 \mathrm{~mm} / \mathrm{yr}$ and $15.0 \mathrm{~mm} / \mathrm{yr}$. An additional a priori constraint is that the slip rate for the Kunlun fault must be larger than the slip rate for the Ganzi-Yushu fault (Chevalier et al., 2017; Van Der Woerd et al., 2002).

We take the Kusai Lake segment of KLF striking $\mathrm{S} 82^{\circ} \mathrm{E}$ as the main fault (Text S5.2 in the supporting information). In the optimal model, the Kunlun fault slips at $\sim 6.4 \mathrm{~mm} / \mathrm{yr}$ below $18.2 \mathrm{~km}$, and the Ganzi-yushu fault creeps at $4.1 \mathrm{~mm} / \mathrm{yr}$ below $16.1 \mathrm{~km}$. While the minimum weighted residual sum of squares (WRSS) is $\sim 1.7$, the results show that a series of other models are also acceptable with a similar fit to the data (Figure 4). In the following analysis, any model with data misfit greater than the optimal model but within the $70 \%$ confidence level is chosen as an acceptable candidate model.

The residual post-Kokoxili velocities with respect to all acceptable models define potential range of postseismic transients in the nominally interseismic CMONOC-II and XDT GPS velocities (Figures 6 and 7). The potential postseismic transients in the CMONOC-II and XDT GPS velocities roughly follow asymmetric left-lateral shear across the fault: the peak velocity values on the southern side are 2 to 3 times larger than on the northern side. Except for the abnormal and poorly-constrained postseismic transients at some GPS sites (e.g., abnormal pattern at J377, and poorly-constrained pattern at G344 and QHTT, see Text S5.2 in the supporting information for more discussions), postseismic transients south of the KLF are well defined and approximately follow a unimodal "pulse" with a peak at $\sim 30-45 \mathrm{~km}$ south of the fault. Conversely, the locus of the postseismic transients maximum north of the fault is not well identified, located somewhere $20-50 \mathrm{~km}$ north of the fault. 


\subsubsection{Velocity interpolation}

We use a physically-based approach in which the secular velocities at target sites are derived from inversion of pre-Kokoxili GPS velocities on the basis of continuous deformation assumption (Shen et al., 1996; Shen et al., 2015) rather than a geometrically-based interpolation method (Haines \& Holt, 1993), in order to avoid outlier errors influencing spatial differentiation between observations. This approach yields a RPT of $3.9 \pm 1.1 \mathrm{~mm} / \mathrm{yr}$ in the direction $\mathrm{N} 73 \pm 11^{\circ} \mathrm{E}$ at JB51, resulting in a large anticlockwise azimuth discrepancy of $28^{\circ}$ anticlockwise with respect to the benchmark result at that station (section 3.1).

\subsubsection{Elastic block models}

Because 2D screw dislocation models cannot be used to consider the rotation and faultnormal components of deformation as well as the effects of geometrical fault complexities, we now assess the model performance of elastic block models in explaining the pre-Kokoxili GPS velocities.

Both pre-Kokoxili GPS velocities and geologic slip rates are used to constrain the elastic block model (Text S6 in the supporting information). Of all the geologic slip rates used, the most important constraints are $11.5 \pm 2.0 \mathrm{~mm} / \mathrm{yr}$ between $94^{\circ} \mathrm{E}$ and $99.6^{\circ} \mathrm{E}$ (Chevalier et al., 2017; Van der Woerd et al., 1998; Van Der Woerd et al., 2002), 10.0 $\pm 1.5 \mathrm{~mm} / \mathrm{yr}$ on the Kusai Lake segment (Li et al., 2005) along the Kunlun fault, and $6.0 \pm 2.0 \mathrm{~mm} / \mathrm{yr}$ (Chevalier et al., 2017) on the northern and central Ganzi-Yushu fault.

The model fits the pre-Kokoxili GPS data along the Qingzang Road well (Figure S11), and the derived slip rates match the long-term geologic slip rates (Figure S12). The residuals at the XDT GPS sites (interseismic velocities minus model prediction) resemble asymmetric shear across the coseismic rupture (Figure 6). This approach yields a RPT at JB51 of 3.3 \pm 0.8 $\mathrm{mm} / \mathrm{yr}$ in the direction $\mathrm{N} 84 \pm 10^{\circ} \mathrm{E}$, which also does not match well the benchmark RPT (azimuth discrepancy of up to $17^{\circ}$ ).

\subsection{Assessing the model-dependent residual postseismic transients}

The first-order feature of the RPT derived in the previous sections is similar-asymmetric leftlateral shear across the 2001 rupture. But second-order features are different (Figure 6). Indeed, the reliability of the RPT derived in the previous sections depends on the inherent properties of each method and how well the data resolve the different model parameters.

The merits of using 2D models for our purpose include: (1) few parameters need to be constrained, (2) convenience for exploring modeling uncertainties, and (3) good performance at the benchmark sites (e.g., JB51). Due to intrinsic limitations of the 2D models, however, the resulting RPT are parallel to the fault strike. This may be inappropriate to model effects near the ends of faults, which are expected at sites DUOX and YZSE (as shown in the RPT derived by the other two methods). When compared to the pre-Kokoxili data, the postKokoxili data show excessive southward motion at sites DUOX and YZSE, and we therefore correct such a bias in the results from 2D models (post-Kokoxili fault normal velocity minus pre-Kokoxili rate, which is obtained from spatial interpolation at DUOX and YZSE). The 2D model-derived RPT at three sites along the trace of the Xidatan segment are close to zero, which is inconsistent with the RPT at other nearby sites. This is due to mis-location of these sites on the wrong side of the fault in the $2 \mathrm{D}$ model, resulting into inappropriate effects of fault locking on the Xidatan segment at these sites. 
For the interpolation method, the velocity interpolated at each target site is a spatial average of the pre-Kokoxili velocities on both sides of the 2001 rupture (by optimizing relative weight between data and the spatial smoothing applied in the inversion). Because of the scarcity of the input data, this method provides us an over-smoothed deformation field. The RPT at JB51, for example, results in a significant azimuth bias (as well as at FHSN). The rates of the RPT at the sites within $70 \mathrm{~km}$ north of the Xidatan segment are in magnitude 1-2 $\mathrm{mm} / \mathrm{yr}$ larger than the rates derived from the 2D and 3D block models. The RPT show subtle, but non-negligible, northwest-directed motion at the three sites along the Xidatan segment, which exhibit spatial consistency with respect to the RPT at other nearby sites. This highlights the advantage of this method that can deal with the effect of fault-geometry complexities (here the coexistence of two fault segments with different strike) on the observed surface deformation.

We do not place too much significance on the modeling results from elastic block models, although these models fit well data for the pre-Kokoxili GPS velocities along the Qingzang Road, and provide RPT similar to those from the interpolation method, with uncertainties less than $1 \mathrm{~mm} / \mathrm{yr}$ obtained using standard error propagation. Indeed, limitations are: (1) parameters characterizing block motions are not well resolved, considering the distribution of GPS sites (sparse, isolated, and unevenly distributed) and the geometry of blocks (e.g., long, thin Bayan Har (Songpan-Ganzi) block), and hence, slip partitioning between the Kunlun and Ganzi-yushu faults is not well resolved; (2) the complexities in the deformation field, such as distributed strain, cannot be well evaluated. That is, the model predictions are sensitive to loosely resolved model parameters, making the level of uncertainties difficult to assess (Text S6 in the supporting information).

Clearly seen from the comparisons presented above are the pros and cons of different realizations of the model-dependent RPT. The preferred models are those derived from the 2D dislocation approach and from velocity interpolation method. However, we cannot assert here which one is better than the other. The weighted average of the three realizations of RPT is finally used to represent the pre-Kokoxili velocities at the CMONOC-II campaign GPS and XDT cGPS sites. The RPT derived from the 3D block model is down-weighted: 1-sigma uncertainties are respectively two times and six times larger for the east-directed and northdirected RPT, making the standard deviations up to $1.3 \mathrm{~mm} / \mathrm{yr}$ and $4.0 \mathrm{~mm} / \mathrm{yr}$ for the eastdirected and north-directed components.

\subsection{New realization of postseismic relaxation time series}

Subtracting the secular deformation from the Xidatan GPS position time series, we obtain postseismic relaxation time series. The postseismic relaxation time series show (1) active postseismic transients at the near- and intermediate-field sites (Figure 8: YZSE and DUOX); and (2) asymmetric postseismic deformation across the fault (more active deformation to the south of the coseismic rupture). At site YZSE and DUOX, the 2008-2015 cumulative eastwest directed displacements are respectively 35-55 $\mathrm{mm}$ and 40-70 $\mathrm{mm}$ (70\% confidence level).

3.5 Diffusion of postseismic transients

As coseismic stresses diffuses away from the source region, velocity "pulses" appear in the near- and intermediate-field GPS and InSAR observations that decay with time and propagate away from the fault into the adjacent regions (e.g., Li \& Rice, 1987; Thatcher, 1983). This process is highlighted by a data compilation with 2001.9-2002.9, 2003.8-2004.9, and 
2007/2009-2015 postseismic transients superimposed on the same figure (Figure 7). The amplitude of deformation has been asymmetric since the first year following the earthquake and it decreases with time. The peaks of early rapid deformation (red dots in Figure 7) are located respectively $\sim 20-30 \mathrm{~km}$ south and 10-20 km north of the fault. Then, comparing the locations of peak of deformation between the period 2001.9-2002.9 and the period 2007-2015, GPS measurements show that postseismic transients following the 2001 diffuse away from the fault with time. South of the rupture, the locus of deformation shifted by $\sim 10-25 \mathrm{~km}$ southward during the period 2002-2007. This pattern suggests that viscoelastic relaxation at greater depth took over the more rapid effect due to a combination viscoelastic relaxation plus afterslip in the shallower depth a few years after the 2001 event.

\section{Modeling postseismic deformation}

Poroelastic rebound (e.g., Peltzer et al., 1998), afterslip (e.g., Shen et al., 1994), and viscoelastic relaxation (e.g., Pollitz et al., 2001) are commonly used to interpret postseismic geodetic observations. Poroelastic rebound occurs as earthquake-induced pore-pressure changes dissipate in the porous shallow crust. The spatial scale of surface deformation caused by poroelastic rebound depends on where the earthquake-induced pressure changes are significant and might be limited to an area $\sim 10-20 \mathrm{~km}$ from the coseismic rupture (e.g., Peltzer et al., 1998). For the Kokoxili case, the available post-Kokoxili GPS data do not allow resolving poroelastic effects, due to low spatial resolution of the GPS data. Furthermore, poroelastic rebound induces primarily vertical deformation (e.g., Peltzer et al., 1998), which is not visible in our cGPS time series. Hence, we only assess the role of afterslip and viscoelastic relaxation in the following sections.

Note that postseismic transients of the 1997 Mw7.6 Manyi, 2008 Mw7.9 Wenchuan, 2008 Mw7.1 Yutian, and 2008-2009 M6 Qaidam earthquakes are not considered in this study, as potential postseismic transients from these earthquakes should be small at our GPS sites.

\subsection{Choice of Kokoxili earthquake coseismic slip models}

Coseismic slip models are required to drive both afterslip on the fault plane and postseismic "flow" in the viscoelastic substrate. Two coseismic slip models, with vertical fault planes, were used to model the postseismic deformation for the 2001 event: one model was derived from surface offset data (Xu et al., 2002) and observed coseismic GPS displacements (Wang et al., 2003a) and the other model relies on InSAR observations (Lasserre et al., 2005). The GPS-derived slip model fits the GPS data well. The InSAR-derived slip model yields nearfield displacements smaller than the observed coseismic GPS displacements along the Qingzang Road. That model lacks enough coseismic slip on the Kunlun pass fault because of InSAR decorrelation in the vicinity of this fault section. The near-field deformation due to viscoelastic relaxation predicted from InSAR-derived slip model is thus smaller in amplitude than the one predicted from the GPS-derived slip model.

In addition to these published slip models using vertical fault planes, we also consider the possibility of coseismic faulting on non-vertical fault planes. That is because (1) geodetic observations suggest a minor asymmetry in the coseismic deformation field (Ren \& Wang, 2005; Wan et al., 2008) and (2) geologic field work and optical image correlation present evidence for dip-slip motion in addition to strike-slip (Klinger et al., 2006). We tried to invert GPS-derived coseismic displacements (Wang et al., 2003a) and InSAR line-of-sight displacements (Lasserre et al., 2005) for slip distribution on non-vertical coseismic rupture planes, and found that the data available cannot constrain a model consistent with 
independent geological and geophysical observations for the Kunlun pass fault. The patterns of inverted coseismic slip exhibit primarily transtensional on a south-dipping Kunlun pass fault, which is inconsistent with geological and geophysical evidence for the presence of thrust motion (Klinger et al., 2006; Tocheport et al., 2006). Another candidate coseismic slip model (Wan et al., 2008) reveals reverse slip on a south-dipping Kunlun pass fault, which is inconsistent with geological field work showing that the northern side of the fault went up to the east of $\sim 93^{\circ} \mathrm{E}$ (Klinger et al., 2006).

In the follow-up modeling efforts, we will use the coseismic slip model of (Wang et al., 2003a), which is the simplest model considering the ratio of asymmetry in coseismic deformation and the quality of geodetic data.

\subsection{Assessing the role of afterslip}

Afterslip on and below the coseismic rupture fault plane initiates immediately after an earthquake, and may last for few years (e.g., Bruhat et al., 2011). Viscoelastic relaxation also begins right after an earthquake, but for large earthquakes it may last several decades (e.g., Kenner \& Segall, 2000; Vergnolle et al., 2003). Therefore, it is necessary to explore the relative importance of afterslip and viscoelastic relaxation processes in explaining the postKokoxili deformation, particularly for the early rapid deformation.

\subsubsection{Kinematic afterslip inversion}

Kinematic afterslip models, no matter how simple they are, yield afterslip distributions that match well the 2001.9-2002.9 post-Kokoxili displacements (Figure S17). The estimated slip distribution may, however, be mechanically implausible because the magnitude of inverted slip may exceed the value allowed by coseismic stress loading. This is in part due to the fact that the inverse problem is intrinsically under-determined. This can also be due to that deformation caused by other mechanisms (viscoelastic relaxation) is mapped into afterslip. Nonetheless, such inversions are useful as they provide some hints about the post-Kokoxili physical processes at work below the coseismic rupture. For example, if deep afterslip is allowed to occur at depth between $16.5 \mathrm{~km}$ and $46.5 \mathrm{~km}$, left-lateral afterslip is $\sim 1.4 \mathrm{~m}$ between $92.4^{\circ} \mathrm{E}-93.7^{\circ} \mathrm{E}$ (Figure 9), which corresponds to $20 \%$ to $30 \%$ of the coseismic slip that occurred at shallow depth-between the surface and $16.5 \mathrm{~km}$ depth. The corresponding moment magnitude of the afterslip is $1.63 \times 10^{20} \mathrm{~N} \mathrm{~m}$, equivalent to a Mw7.44 earthquake (with a shear modulus $30 \mathrm{GPa}$ ), which is $\sim 30 \%$ of the geodetic estimate for the coseismic moment magnitude. Note that the estimated afterslip is unrealistically large and we will further explore this issue in section 4.2.2.

\subsubsection{Stress-driven afterslip simulations}

To circumvent the limitations of kinematic slip inversion, while still consider the data available, we perform stress-driven afterslip simulations in which afterslip is the response to coseismically-induced stress changes. In the first test, frictionless afterslip at $16.5-46.5 \mathrm{~km}$ is required to relieve the coseismic stress change. In the second set of simulations, afterslip is governed by the frictional properties on the fault plane.

To fit the 2001.9-2002.9 GPS displacements in the frictionless afterslip inversion, cumulative left-lateral slip, greater than $0.5 \mathrm{~m}$ with a maximum of $1.5 \mathrm{~m}$ just below the area of maximum coseismic slip, is located at depth of 16.5 to $34 \mathrm{~km}$, below the region bearing most significant 
coseismic slip (Figure 9). The estimated amplitude of slip corresponds to the upper bound permitted by the coseismic stress loading and the data. The geodetic moment magnitude of the afterslip is $1.7 \times 10^{20} \mathrm{~N} \mathrm{~m}$, equivalent to a $\mathrm{Mw} 7.45$ earthquake.

In the second stress-driven afterslip simulation, for simplicity, we assume that steady-state is attained immediately after the earthquake and rate-strengthening friction applies; afterslip is limited to regions on the fault plane below $16.5 \mathrm{~km}$ that is assumed to have rate-strengthening friction; only strike-slip component is considered (shear traction imparted by the coseismic rupture in the fault dip direction is minor with respect to that in the strike direction). Coupled afterslip and viscoelastic relaxation are not considered (at least stress reloading of the fault patches showing significant afterslip may be insignificant in the time period considered). Our methodology follows similar stress-driven afterslip simulations developed in previous studies (Barbot et al., 2009; Hearn et al., 2002). The initial velocity is determined by

$$
v\left(0^{+}\right)=v_{\text {ref }} \exp \left(\frac{\Delta \tau}{(A-B) \sigma}\right)
$$

in which $(A-B)$ is the friction parameter, $\sigma$ is effective normal stress, $\Delta \tau$ is coseismic shear stress change resolved in the strike direction, and $v_{\text {ref }}$ is a reference velocity. Testing model parameters, we find that: (1) afterslip within the early post-Kokoxili GPS observation period is localized in the region showing significant positive coseismic shear stress change (Figure 9); (2) as shown by decaying rates, the temporal evolution of afterslip follows a non-linear pattern, although the extent of non-linearity decreases with depth (Figure 10); (3) afterslip ends $\sim 6$ years after the event (Figure 10). If $(A-B) \sigma$ is comprised between 0.2 and $0.5 \mathrm{MPa}$, the peak afterslip from December 2001 to November 2002 is $\sim 0.5-0.6 \mathrm{~m}$ (Figure 9), which corresponds to $30 \%$ of the value derived from frictionless afterslip inversion. The equivalent moment is $0.95-1.8 \times 10^{19} \mathrm{~N} \mathrm{~m}$, equivalent to a $\mathrm{Mw}$ 6.6-6.8 earthquake. Considering the potential range of the effective stress (hydrostatic and lithostatic stress), values for $(A-B)$ should be in the range $10^{-4}-10^{-3}$, similar to the neutral stability frictional property for the lower crust gabbro (He et al., 2007). The model-predicted displacements are at most $25 \mathrm{~mm}$ at the GPS sites, one fourth of the observations.

This result suggests that $\sim 6 \%-11 \%$ of the early rapid deformation may be due to afterslip. That ratio will increase if the contribution from shallow afterslip would be considered. Note that the patterns of rate-strengthening governed afterslip are sensitive to the details of the distribution of coseismic slip. Indeed, the coseismic slip model used in this study remains too coarse, rendering the modeled afterslip concentrated along a narrow strip just below the coseismic rupture. Rate-strengthening afterslip simulations using a coseismic slip model similar to Wan et al. (2008) show that strike-slip component of afterslip is distributed within a broader region at $20-35 \mathrm{~km}$ depth, while the peak slip decreases to $\sim 0.20-0.25 \mathrm{~m}$, and it accounts for $\sim 15 \%-20 \%$ of the early rapid deformation.

The fact that afterslip almost levels off six years after the 2001 event, as revealed in the ratestrengthening friction governed afterslip simulations, indicates that viscoelastic relaxation is the primary mechanism after that period.

\subsection{Specifying rheological model geometries}

When modeling viscoelastic relaxation for 3D postseismic deformation field, we probe rheological stratification that involves two main components: (1) rheological model geometry that is usually 3D and (2) rheological constitutive parameters. In our modeling efforts, we 
start with the simplest case consisting of an elastic upper crust (UC) overlying a viscoelastic half-space (Model A, Figure 11a). Next, we consider the effects of layering (Model B, Figure 11b): a viscoelastic lower crust (LC), with Moho offset at the southern margin of the Qaidam Basin, is sandwiched between the UC and viscoelastic upper mantle (UM). To test the effects of assigning the position of boundary across which LC goes from softer to stiffer, we consider three possibilities: (1) only one boundary defined by the Kunlun fault (Model C, Figure 11c); (2) only one boundary along the southern margin of the Qaidam Basin (Model D, Figure 11d); (3) an extended boundary with transitional properties (Model E, Figure 11e). To fit the far-field observations south of Wudaoliang (Yellow triangle in Figure 1), the last model includes an additional boundary trending $\mathrm{S} 82^{\circ} \mathrm{E}$ in the vicinity of the Jinsha River suture (Model F, Figure 11f). The thickness of the elastic UC is set to $16.5 \mathrm{~km}$, roughly consistent with the maximum depth of coseismic slip and $95 \%$ cutoff depth in seismicity (Wei et al., 2010). We do not consider uncertainties regarding the exact geologic structures beneath the Kunlun Shan (e.g., Moho offset or under-thrusting fault), and, for simplicity, the Moho for our Qaidam Basin model is at a depth of $48 \mathrm{~km}$, which is $20 \mathrm{~km}$ shallower than the Moho in the Songpan-Ganzi terrane.

In the following sections, the term homogeneous only applies for mechanical properties. That is, the lower crust is homogeneous if the viscosity is the same in this layer, even though lateral variation of the Moho depth does occur.

\subsection{Assessing homogeneous viscoelastic lower crust}

We use the software package Relax (Barbot \& Fialko, 2010) to model the postseismic viscoelastic relaxation. To set up a background viscosity profile, we first define laterally homogeneous and depth-dependent viscosity; to implement lateral variations of viscosity, we next introduce cuboids whose viscosities differ from the background values. Only homogeneous elastic properties are considered and elastic modulus is set as $30 \mathrm{GPa}$. We adapt the input parameters to reflect the different conventions used by different codes, such as PSGRN/PSCMP (Wang et al., 2006) and VISCO1D (Pollitz, 1997).

The data constraint in the first year is the cumulative displacement with the contribution from rate-strengthening afterslip removed. Such a simple correction may not give us the exact deformation due to viscoelastic relaxation, but we further discuss the effects of this correction in the section 5.2.

For the Model A (Figure 11a), we find that no matter how we assign homogeneous or heterogeneous viscosities (Maxwell rheology) across the fault, azimuth discrepancies arise in the near field between the model predictions and observations (similar to Figure 12). To align with the observations, the model predictions for GPS sites located north of the Kunlun Pass fault (KLGD, BS33, NACH, XIDT, and GM10) and south of the Kunlun Pass fault (GL43, BDGD, and GL53) should be rotated respectively clockwise and anti-clockwise.

The azimuth misfit does not mainly stem from potential bias in the data, but should be due to model limitations. That is because the first-order features of the GPS measured postseismic transients are reliable, although they still contain potential biases which are related to uncertainties in the estimates of pre-Kokoxili velocities.

If additional reverse slip would be prescribed on a south dipping Kunlun pass fault in the coseismic slip model, the viscoelastic relaxation will induce horizontal motion toward the fault, which reduces the azimuth errors at the GPS sites south of the 2001 rupture. However, 
it would also increase the azimuth errors at the sites north of the rupture. Likewise, afterslip with both strike slip and reverse slip cannot be used to reduce the azimuth errors in the near field.

Introducing a larger effective viscosity for the UM compared to the LC reduces the azimuth discrepancies between model and data (Model B, Figure 11b). Hence, in the follow-up models, the viscosity of the UM is set to $1.0 \times 10^{20}$ Pas, the best-fit value based on a grid search for the viscosities of the LC and UM in Model B.

The later the post-Kokoxili GPS observations used, the larger the optimal viscosity of Maxwell rheology for the Model B is (Figure 13), indicating that a transient (e.g., biviscous) rheology is needed to fit the observations. However, for simplicity, we implement Maxwell rheology. For the 2001.9-2002.9 postseismic displacements, the estimated viscosity is $2.5 \times 10^{18}$ Pas, and for the 2007-2015 Xidatan cGPS time series and the 2009-2015 postseismic velocities, the estimated viscosity is $\sim 3.0-4.0 \times 10^{19}$ Pas.

If the observations on each side of the fault are used separately to constrain the model, the optimal viscosity constrained by the Xidatan GPS time series on the northern side is twice the corresponding value constrained by the data south of the Kunlun fault (Figure 13). The model constrained by the 2001.9-2002.9 data on both sides over-predicts the displacements in the northern side (Figure 12). Therefore, this shows that lower crustal and/or upper mantle viscosity heterogeneities are present, requiring models with lateral heterogeneity.

4.5 Assessing laterally heterogeneous viscoelastic lower crust

In our models, we implement heterogeneity in the LC by embedding cuboid(s) with different rheology in the LC. Three abutting cuboids, more than $750 \mathrm{~km}$ long in total and $200 \mathrm{~km}$ wide, are located beneath the Qaidam Basin $(60 \mathrm{~km}$ north of the Kunlun fault, Figure 11c-f and Figure S18). Three additional cuboids that represent a possible rheological transition zone are sandwiched between the LC beneath the Qaidam Basin and the LC beneath the SongpanGanzi terrane (Figure 11c-f and Figure S18).

The Maxwell viscosities are respectively parameterized by $\eta_{S}, \eta_{Q}$, and $\eta_{T}$ for the LC beneath the Songpan-Ganzi terrane, Qaidam Basin, and the transition zone in between. The parameters to be estimated are $\eta_{S}$, and $\eta_{Q} / \eta_{S}$ for the models with only one heterogeneity boundary either along the Kunlun fault $\left(\eta_{T}=\eta_{Q}\right.$, Figure $\left.11 \mathrm{c}\right)$ or along the southern margin of the Qaidam Basin $\left(\eta_{T}=\eta_{S}\right.$, Figure 11d). For the case where rheology in the transition zone is different from the rheologies in the adjacent regions, we also have to consider the ratio $\eta_{T} / \eta_{S}$ (Figure 11e).

Overall, models with LC heterogeneities fit the data better than the model with homogeneous LC (Models A-B versus Models C-D in Table 3, Figure 12 versus Figure 14). For the models with only one viscosity boundary in LC, Model C fits the data better than the Model D, although none of them provides satisfactory data-fitting (Figure 14 and Figure S19-S21): For the cumulative displacement during the first year (Figure 14), Model C under-predicts the farfield data on both sides of the fault (at GPS sites GL63, JB51, GL78, GM10, and JB30); to the north of the Kunlun fault, model predictions of Model D match better the observations at the far-field sites, but predictions exceed the observations in the near field. Model C and D also cannot fit well the 2007-2015 GPS time series data, with a misfit similar to what was obtained for the first year (Figure S19-S21), suggesting that the rheological structure beneath the Kunlun Shan differs from the neighboring regions. Therefore, we further increase the 
model geometry complexity by incorporating a transition zone between the Songpan-Ganzi terrane and the Qaidam Basin (Model E, Figure 11e).

In Model E, the parameters of interest are $\eta_{S}, \eta_{Q}$, and $\eta_{T}$. In the modeling efforts using model geometries following Models $\mathrm{B}$ and $\mathrm{C}$, a robust conclusion is that the transient and steadystate viscosities of the LC beneath the Songpan-Ganzi terrane should be $2.0 \times 10^{18}-3.0 \times 10^{18} \mathrm{~Pa}$ $\mathrm{s}$ and $\sim 2.0 \times 10^{19} \mathrm{~Pa} \mathrm{~s}$, respectively (Table 4). We therefore fix $\eta_{S}$ at $3.0 \times 10^{18} \mathrm{~Pa} \mathrm{~s}$ and $2.0 \times 10^{19} \mathrm{~Pa}$ s, respectively, when fitting the early and later stage GPS data, rendering the modeling work less computationally intensive. The parameters yet to be determined are $\eta_{T} / \eta_{S}$ and $\eta_{Q} / \eta_{s}$. In that case, the data used in this study cannot resolve well the LC heterogeneity across the southern margin of the Qaidam Basin, because a lack of data in the Qaidam Basin. The optimal values of $\eta_{T} / \eta_{S}$ are 1.6 and 3.5, respectively, in the first year and during the time period between 2007 and 2015, slightly smaller than the values $\eta_{Q} / \eta_{S}$ being 2.0 and 4.0 for the Model C $\left(\eta_{T}=\eta_{Q}\right.$, Table 4). The optimal values of $\eta_{Q} / \eta_{S}$ for the Model E reach the upper limit (20.0) allowed in our modeling efforts. The Model E fits the data better than the Model $\mathrm{C}$, as the weighted residual sum of squares is smaller (Table 3), but the improvement in data fitting is not visually obvious (Figure S23, similar to blue vectors in Figure 12).

All the heterogeneous models tested yet under-predict the far-field displacements in the first year at GPS sites south of the Kunlun fault (sites GL63, JB51, GL78 in Figures 14-15). The model predictions for the period 2007-2015 are in magnitude marginally smaller than the observations at the far-field Xidatan GPS sites (Figure S20), but the uncertainties of the derived postseismic transients there are quite large (because the RPT there are not well recovered at the sites QHTT and TUOT, as in Figures 6-7). However, extrapolating the RPT north of the Fenghuo Shan to the region in the Qiangtang terrane, far-field postseismic transients in the Qiangtang terrane should still be very active six years after the 2001 event (perhaps about $2 \mathrm{~mm} / \mathrm{yr}$ in the $\mathrm{S} 82^{\circ} \mathrm{E}$ direction, Figure 7).

To better fit the far-field data in the first year, we explore four strategies: (1) to reduce the viscosity of the UM, (2) to thicken the LC, (3) to include the deep afterslip, and (4) to customize LC heterogeneity across the Jinsha River suture $(\sim 75 \mathrm{~km}$ southwest of Wudaoliang).

As the viscosity of the UM gets closer to viscosity of the LC beneath the northern SongpanGanzi, the model can fit the far-field data, although it is at the expense of deteriorating nearfield data-fitting (red and purple vectors in Figure S24). For example, to fit the far-field data in the first year, the viscosity of the upper mantle should be smaller than $\eta_{S}$. We set it the same as $\eta_{S}$ in the following two tests. When the $\eta_{S}$ is $3.0 \times 10^{18} \mathrm{~Pa} \mathrm{~s}$, the azimuth errors in the near field increase (similar to the results for Model A in Figure 12); when the $\eta_{S}$ is $2.0 \times 10^{18}$ $\mathrm{Pa} \mathrm{s}$, the model over-predicts the near-field observations.

Increasing the thickness of the LC to $100 \mathrm{~km}$ (the LC in the Qaidam Basin is $80 \mathrm{~km}$ thick, to retain the $20 \mathrm{~km}$ Moho offset) does not help to remedy the far-field data misfit (blue vectors in Figure S24). To fit the far-field data, $\eta_{S}$ should be $2.0 \times 10^{18} \mathrm{~Pa}$ s, but the model overpredicts the near-field data. If the model fits the near-field data $\left(\eta_{s}=3.0 \times 10^{18} \mathrm{~Pa} \mathrm{~s}\right)$, it underpredicts the far-field data.

Deep afterslip may be a potential source to explain the far-field data misfit in the heterogeneous models. For example, the distribution of afterslip that mimics the kinematic 
afterslip can fit the far-field data well (Figure S17), but the magnitude of deep afterslip required may be too large, given the magnitude of coseismic stress loading (Figure 9).

Finally, we test a model with an additional cuboid embedded in the LC beneath the Qiangtang terrane (Model F, Figure 11f), which is a modification of Model E. It should be noted that Model C-F include additional contribution from afterslip. When compared to the Model C-E, Model F fits better the far field data south of the Kunlun fault (red vectors in Figure 15). In Model F the transient viscosity of the LC beneath the Qiangtang terrane is $4.0 \times 10^{17} \mathrm{~Pa} \mathrm{~s}$, almost an order smaller than that for the LC beneath Songpan-Ganzi. The data misfit achieved by the Model F can be further reduced if the viscosity of the upper mantle is adjusted to a value slightly smaller than $1.0 \times 10^{20} \mathrm{~Pa} \mathrm{~s}$ (but greater than $2.0 \times 10^{19} \mathrm{~Pa} \mathrm{~s}$ ).

All the comparisons, as mentioned above, emphasize the difficulty in fitting far-field data due to uncertainty about the actual origin of the observed deformation. If we stick to a conventional approach, a sound model would be a heterogeneous model with less strength contrast between the LC and UM, such as Model E. In this work, however, we introduced an alternate viscoelastic structure in which the viscosity increases stepwise northward, the strength of the LC is an order of magnitude smaller than the strength of the UM, and afterslip is appended in order to fit the joint information in the near field and far field. The preferred model which contains all of these elements is Model F.

\section{Discussion}

5.1 Space- and time- separable postseismic transients following strike-slip events?

Phenomenologically, space- and time- separable horizontal deformation is a special case of deformation in which the deformation does not disperse spatially over time. If it was applied to postseismic deformation, the spatial pattern of postseismic transients is what we see when the system is fully relaxed, and it decays following only one mode of temporal function. Previous studies on the Mojave earthquakes seem to support space- and time- separable postseismic deformation (Fialko, 2004; Savage \& Svarc, 2009). In the Kokoxili case, however, the GPS observations apparently show that the space- and time- separable deformation does not apply (Figure 7a). Evident in the GPS data are two modes of deformation with different spatial-temporal patterns that should be related to at least two sources (afterslip and viscoelastic relaxation). The data available are not dense enough to assess the exact relative contribution of afterslip and viscoelastic relaxation in the first year. If afterslip were a secondary process during the early period, the remaining postseismic transients during the same period should be due to viscoelastic relaxation. Then, the two modes of deformation visible in the data are dictated by layering of the models (e.g., thickness of the elastic layer) and transient and steady-state viscosities assigned for the viscoelastic medium.

5.2 Comparisons with previous geodetic studies

Previous geodetic studies (Diao et al., 2011; He et al., 2018; Ryder et al., 2011; Shao et al., 2008; Wen et al., 2012) did not explore the possibilities of LC heterogeneity in a way as comprehensive as we have here (Figure 11). The modeling attempts presented here still have limitations and the conclusions depend on how accurately the postseismic transients are derived, especially at our Xidatan GPS sites. Nonetheless, our modeling efforts reveal complexities of the LC rheological structure of the northern Tibetan Plateau. The LC viscosity boundary across the Kunlun fault is undoubtedly required by the GPS data used in 
this study. The LC viscosity boundary along the southern margin of the Qaidam Basin is not well resolved by our data, although it has been already well recognized in previous geophysical (Karplus et al., 2011; Zhu \& Helmberger, 1998) and geodetic studies (He et al., 2018). Another viscosity boundary may be present along the Jinsha River suture, but more far-field data are needed to verify this conclusion (e.g., He et al., 2018). If the far-field GPS observations south of the Fenghuo Shan after 2007 exhibit active postseismic transients, LC rheology anomaly beneath the Qiangtang terrane would be a robust conclusion. A heterogeneous model without a LC viscosity boundary located along the Jinsha River suture can fit the far-field data well, although it over-predicts the near-field displacements at GPS sites BDGD, GL53, and GL57 (Figure 13, Ryder et al., 2011); another heterogeneous model, with elastic upper crust overlying viscoelastic half-space and LC viscosity boundaries along the Kunlun fault and the southern margin of the Qaidam Basin, fit the near- and intermediatefield data well, but systematically underestimates the observed deformation south of the Jinsha River suture (He et al., 2018). Those two limitations of the published heterogeneous models can be much reduced when an additional LC viscosity boundary is set along the Jinsha River suture and the viscosity of upper mantle is much larger than that of the lower crust (similar to Model F in Figure 11).

Estimates of the effective viscosity, in particular the transient viscosity, rely on how accurately relative contributions from afterslip and from viscoelastic relaxation are determined. Postseismic transients due to afterslip may be larger than that predicted by the rate-strengthening afterslip model, considering that we have not modeled the shallow and deeper afterslip that should have occurred. If most of the early rapid deformation was induced by afterslip, one of the consequences in modeling postseismic viscoelastic relaxation would be that univiscous rheology is sufficient to fit both the early and later-stage data. Considering the chemical and physical conditions in the LC beneath the Tibetan Plateau (e.g., high temperature (Owens \& Zandt, 1997)), however, rocks exhibiting both transient and steadystate rheology are more likely (Bürgmann \& Dresen, 2008).

We first compare the optimal viscosities of the LC beneath the northern portion of SongpanGanzi terrane obtained in this study with optimal viscosities estimated using laterally homogeneous models from previous studies. The optimal transient viscosity in our study agrees within uncertainties with the results based on similar data, although including only the first year after the event (Diao et al., 2011), but is two times larger than the optimal transient viscosity $\left(9 \times 10^{17} \mathrm{~Pa}\right.$ s) constrained from post-Kokoxili relaxation GPS time series for the same time interval (Ryder et al., 2011). This is probably due to the fact that the cumulative displacements derived from the 2001-2002 GPS time series cannot constrain the temporal evolution of early rapid deformation as well as the 2001-2012 GPS position time series. The optimal steady-state viscosity in this study is consistent with previous results $\left(\sim 1-2 \times 10^{19} \mathrm{~Pa}\right.$ s) based on 2003-2007/2008 InSAR line-of-sight displacements (Ryder et al., 2011; Wen et al., 2012).

We then compare the optimal viscosities derived from heterogeneous models. The optimal transient viscosity of the LC beneath the northern Songpan-Ganzi terrane in this study $\left(2 \times 10^{18}-3 \times 10^{18} \mathrm{~Pa} \mathrm{~s}\right)$ is two to three times larger than $9 \times 10^{17} \mathrm{Pas}$, the value derived for a model in which heterogeneity occurs along the southern margin of the Qaidam Basin (Ryder et al., 2011) and four to six times larger than $5 \times 10^{17} \mathrm{~Pa}$ s, the value derived from a model in which the viscosity boundary is placed along the Kunlun fault (Shao et al., 2008). The transient and steady-state viscosities for the LC beneath the northern Songpan-Ganzi terrane are marginally larger than the corresponding values $\left(1.5 \times 10^{18} \mathrm{~Pa} \mathrm{~s}\right.$ and $\left.1.5 \times 10^{19} \mathrm{~Pa} \mathrm{~s}\right)$ for 
Burgers rheology constrained by GPS observations from 2001 to 2007 (He et al., 2018). The transient viscosity derived for the Qaidam LC is larger than the value $5 \times 10^{18} \mathrm{~Pa}$ s derived in He et al. (2018). The ratio of viscosity heterogeneity for the steady-state viscosity can be up to 15 , roughly consistent with the value of 10 in He et al. (2018).

Our steady-state viscosity of the lower crust beneath the northern Songpan-Ganzi terrane agrees with those in the plastosphere derived from laterally homogeneous earthquake-cycle deformation models constrained by pre-Kokoxili GPS velocities alone (Hilley et al., 2005; Hilley et al., 2009). Another modeling effort on earthquake-cycle deformation allowing for viscoelastic flow in a mid-crustal layer alone, however, showed that a model with $10^{18.2}-10^{18.8}$ $\mathrm{Pa}$ s layer at 20-30 km depth can explain both pre- and post-Kokoxili velocities (DeVries \& Meade, 2013). Several points, however, should be emphasized: (1) The upper bound $\left(10^{18.8}\right.$ $\mathrm{Pa}$ s), not well defined, is based on pre-Kokoxili GPS velocities; (2) The lower bound on the steady viscosity $\left(10^{18.2} \mathrm{~Pa} \mathrm{~s}\right)$ is constrained by fast post-Kokoxili rate $(62 \pm 4 \mathrm{~mm} / \mathrm{yr})$ at only one near-field site, BDGD.

\subsection{Rheological structure beneath the northern Tibetan Plateau}

Although most geodetic estimates of the lower crustal viscosity are not consistent with corresponding values for the "channel flow" model (e.g., Clark \& Royden, 2000; Royden et al., 1997), we cannot draw conclusions regarding whether the "channel flow" model applies to the northern Tibetan Plateau without considering the difference between the relevant timescales and the trade-off between parameters in the models. Geodetic estimates are accounting for decadal time scale, while the corresponding estimates for the "channel flow" model account for geological time scale. Based on Model F, the transient viscosity of LC south of the Jinsha River suture might be $\sim 4.0 \times 10^{17} \mathrm{~Pa} \mathrm{~s}$; the effective viscosity at the decadal time scale should be an order of magnitude larger $\left(>4.0 \times 10^{18} \mathrm{~Pa} \mathrm{~s}\right)$; and the steady-state viscosities of $\mathrm{LC}$ elsewhere in the northern Tibetan Plateau are of the order of $10^{19} \mathrm{~Pa} \mathrm{~s}$, at least an order of magnitude larger than the corresponding value required by the "channel flow" model $\left(<10^{18} \mathrm{~Pa} \mathrm{~s}\right)$. Furthermore, short-term estimates of the lower crustal viscosity may increase by one to two orders when the data for a longer time scale response are used to constrain a specific mechanical model (e.g., Henriquet et al., 2019). This finding, when combined with our results, suggests that geodetic data may not support the "channel flow" model for the northern Tibetan Plateau. However, estimates of the lower crustal viscosity scale with the layer thickness of the modeled lower crust to a power three (e.g., Henriquet et al., 2019). If we adjust the thickness of the lower crust from $\sim 50 \mathrm{~km}$ (as in our model) to 15 $\mathrm{km}$ (as in the "channel flow" model), south of the Jinsha River suture, geodetic estimates of lower crustal viscosity will decrease by almost one order of magnitude, to $\sim 10^{16} \mathrm{~Pa}$ s, which is consistent with that of the "channel flow" model. Nonetheless, it remains unclear where the $15 \mathrm{~km}$ thick layer would be located in the lower crust (at the top, at the bottom, or at the intermediate depth of the lower crust); when we consider the effects of time-dependent increase of the estimates of viscosity, geodetic estimates might not support the "channel flow" model for the northern Tibetan Plateau (e.g., Henriquet et al., 2019). For the other regions in the northern Tibetan Plateau (e.g., Sonpan-Ganzi terrane), the geodetic estimates are still larger than the corresponding value of the "channel flow" model.

Effective viscosity of the LC may exhibit stepwise increase from the central Tibetan Plateau, across the Kunlun fault, to the Qaidam Basin (Figures 11 and 16). The increase of LC viscosity across the Kunlun fault is a robust feature according to modeling the post-Kokoxili GPS measurements. Less is known about the LC heterogeneity in the Songpan-Ganzi and Qiangtang terrane. The LC viscosity boundaries beneath those two terranes should be related 
to expressions in the surface topography. As the Jinsha River suture defines the boundary between the two terranes (Figure 1), along which topography anomaly does exist, LC heterogeneity should be expected there. The geodetic data used in this study appear to support that feature (to fit the far-field postseismic transients). The topography on both sides of Wudaoliang is relatively flat, but the position of Wudaoliang coincides with a SEE-striking topography bulge ( $200 \mathrm{~m}$ higher than the neighboring regions on both sides). We tested the case with a viscosity boundary located in the vicinity of Wudaoliang and we found that this model can be used to fit the far-field postseismic transients but over-predicts near-field postseismic transients at the GPS sites south of the Kunlun fault.

\section{Conclusions}

We analyzed pre- and post-Kokoxili GPS measurements across the 2001 rupture to better understand the lower crustal heterogeneity in the northern Tibetan Plateau. We again confirm that the trade-off between the estimates of the secular velocities and long-term postseismic transients could not be resolved well by the analysis of GPS position time series alone if preearthquake observations are insufficient, as suggested by studies of Landers and Hector Mine earthquakes in California (Liu et al., 2015). It is because of this trade-off that we must interpret both interseismic and postseismic deformation signals cautiously. In fact, operating a GPS network after a large earthquake in a region without any pre-earthquake geodetic observations nearby might be partly futile unless the observations last for decades or longer until the postseismic transients die out. Nonetheless, for the Kokoxili case, we extracted residual postseismic transient velocities in the nominally interseismic GPS velocities derived from post-Kokoxili GPS measurements and show that postseismic deformation was still significant during the period 2007-2015 when its maximum rate reaches $\sim 10 \mathrm{~mm} / \mathrm{yr}$. We show that residual postseismic transient velocities are characterized by high shear strain rate across the KLF.

GPS measurements across the KLF since 2001 reveal that postseismic transients diffused away from the coseismic rupture through time. It is the first direct observational evidence for that pattern for a large strike-slip earthquake in the Tibetan Plateau. This is also clear evidence for space- and time- inseparable postseismic transients that signify multiple physical processes and complexity of rheological property. GPS measurements also reveal asymmetric postseismic deformation following the 2001 Kokoxili earthquake. Postseismic transients to the south are larger than those to the north, with the asymmetry ratio of 2 one year after the 2001 event and more than 3 six years later.

We explain the early rapid postseismic transients during the first one year by both deep afterslip and viscoelastic relaxation. In the stress-driven afterslip models, the maximum afterslip governed by rate-strengthening friction is $\sim 0.5 \mathrm{~m}$, which is $30 \%$ of the upper bound $(1.5 \mathrm{~m})$ derived from frictionless afterslip model. The stress-driven afterslip appears to be localized along a narrow band above $\sim 25 \mathrm{~km}$ and below the fault patches with large coseismic slip. Afterslip accounts for $\sim 10 \%$ of the signals in this period, but the proportion can increase to $\sim 20 \%$. The remaining signals are ascribed to viscoelastic relaxation.

Based on our Xidatan cGPS observations during the period 2007-2015, we ascribe the ongoing postseismic transients mainly to active viscoelastic relaxation given that the ratestrengthening friction governed afterslip almost level off six years after the 2001 event. When we consider viscoelastic relaxation to fit all the GPS data available in this study, transient (e.g., biviscous) rheology is required to explain the post-Kokoxili GPS data. If Maxwell 
rheology is alternatively implemented, the lower crust viscosity (Maxwell body) estimated for the northern Songpan-Ganzi terrane is as low as $2 \times 10^{18}-3 \times 10^{18} \mathrm{~Pa}$ s from the early rapid data in the first year, and it increases to $\sim 2 \times 10^{19} \mathrm{~Pa} \mathrm{~s} 6-14$ years after the event. However, the transient viscosity value $\left(2 \times 10^{18}-3 \times 10^{18} \mathrm{~Pa}\right.$ s) should be close to the lower bound value because the role of afterslip may be under-estimated.

Post-Kokoxili GPS measurements reveal that heterogeneity exists in the lower crust beneath the northern Tibetan Plateau. Overall, the transient and steady-state viscosities of the lower crust north of the Kunlun fault are $\sim 2$ (greater than 2 is acceptable) and $\sim 4$ (greater than 2 is acceptable) times the viscosities of lower crust in the southern side (Figure S25), respectively. However, the rheological properties of the lower crust beneath the Kunlun Shan (just to the north of the Kunlun fault) show intermediate viscosity values compared to those of the lower crust for the abutting regions (Figure S26, the Songpan-Ganzi terrane and the Qaidam Basin).

To thoroughly explore the effects of afterslip on and below the coseismic rupture and the rheological structure of the northern Tibetan Plateau, geodetic data with better spatialtemporal resolution should be used in the follow-up studies. The stepwise increase of the viscosities of the lower crust from the Qiangtang terrane across the Kunlun fault and to the Qaidam Basin should be one of the foci in the follow-up studies on the postseismic deformation field following the 2001 event. We anticipate that models that show this feature can afford us a viable alternative to reconcile the far-field and near-field GPS measurements (He et al., 2018).

\section{Acknowledgements}

We thank two anonymous reviewers for their constructive reviews that helped improve this manuscript. We thank Editor Paul Tregoning and Associate Editor Mike Taylor for their comments. This work has been supported by National Key Research and Development Project of China (2018YFC1504104), ANR project ANR-005-CATT-0006, and National Natural Science Foundation of China (40802052). The first author gratefully acknowledges the support of K.C.Wong Education Foundation, Hong Kong and CNRS. Authors thank P. Tapponnier for inspiring discussions that eventually led to this work. We thank Min Wang for sharing the CMONOC-II cGPS data. The first author thanks Sylvain Barbot for his guide to use Relax. We thank Shiming Liang for sharing GPS position time series at JB51 that was used in Liang et al. (2013). We thank Hua Wang for sharing the CMONOC-II campaign GPS time logs. We thank Cecile Lassere for sharing the InSAR measurements of the coseismic deformation associated with the 2001 Kokoxili earthquake (Lasserre et al., 2005). The first author thanks Yangmao Wen and Bei Xu for discussions on the InSAR data. The first author thanks Jack Loveless for sharing his block model. The Xidatan cGPS network was initially constructed by Guihua Chen and Cyril Romieu, and maintained later by Guihua Chen, Maurin Vidal, Yann Klinger, and Jean-Mathieu Nocquet. Mr. Zhenguang Chang, Feng Li, Renmao Yuan, Kang Li, and Guoyan Jiang helped a lot in the field work for station maintenance. The Xidatan cGPS time series used in this study are available in the Open Science Framework (https://doi.org/10.17605/OSF.IO/V72GF). GPS data from other sources can be found in Zhang et al. (2004), Ren \& Wang (2005), and Zheng et al., (2017). We are indebted to the numerous people who, over the years, maintained the CMONOC and Xidatan GPS networks and collected the data used in this study. Most of the numerical computations were performed on the S-CAPAD platform, IPGP, France. All the figures were generated using the Generic Mapping Tools (Wessel \& Smith, 1998). The authors declare that we have no competing financial interests. 


\section{References}

Altamimi, Z., Collilieux, X., \& Métivier, L. (2011). ITRF2008: an improved solution of the international terrestrial reference frame. Journal of Geodesy, 85(8), 457-473, doi:10.1007/s00190-011-0444-4

Bürgmann, R., \& Dresen, G. (2008). Rheology of the Lower Crust and Upper Mantle: Evidence from Rock Mechanics, Geodesy, and Field Observations. Annual Review of Earth and Planetary Sciences, 36(1), 531-567, doi:10.1146/annurev.earth.36.031207.124326

Bai, D., Unsworth, M. J., Meju, M. A., Ma, X., Teng, J., Kong, X., Sun, Y., Sun, J., Wang, L., Jiang, C., Zhao, C., Xiao, P., \& Liu, M. (2010). Crustal deformation of the eastern Tibetan plateau revealed by magnetotelluric imaging. Nature Geoscience, 3, 358, doi:10.1038/ngeo830

Barbot, S., \& Fialko, Y. (2010). A unified continuum representation of post-seismic relaxation mechanisms: semi-analytic models of afterslip, poroelastic rebound and viscoelastic flow. Geophysical Journal International, 182(3), 1124-1140, doi:10.1111/j.1365-246X.2010.04678.x

Barbot, S., Fialko, Y., \& Bock, Y. (2009). Postseismic deformation due to the Mw 6.02004 Parkfield earthquake: Stress-driven creep on a fault with spatially variable rate-and-state friction parameters. Journal of Geophysical Research: Solid Earth, 114(B7), doi:10.1029/2008jb005748

Beaumont, C., Jamieson, R. A., Nguyen, M. H., \& Lee, B. (2001). Himalayan tectonics explained by extrusion of a low-viscosity crustal channel coupled to focused surface denudation. Nature, 414, 738, doi:10.1038/414738a

Bruhat, L., Barbot, S., \& Avouac, J.-P. (2011). Evidence for postseismic deformation of the lower crust following the 2004 Mw6.0 Parkfield earthquake. Journal of Geophysical Research: Solid Earth, 116(B8), doi:10.1029/2010jb008073

Chen, Q., Freymueller, J. T., Wang, Q., Yang, Z., Xu, C., \& Liu, J. (2004). A deforming block model for the present-day tectonics of Tibet. Journal of Geophysical Research: Solid Earth, 109(B1), doi:10.1029/2002jb002151

Chevalier, M.-L., Leloup, P. H., Replumaz, A., Pan, J., Métois, M., \& Li, H. (2017). Temporally constant slip rate along the Ganzi fault, NW Xianshuihe fault system, eastern Tibet. GSA Bulletin, 130(3-4), 396410, doi:10.1130/b31691.1

Clark, M. K., \& Royden, L. H. (2000). Topographic ooze: Building the eastern margin of Tibet by lower crustal flow. Geology, 28(8), 703-706, doi:10.1130/0091-7613(2000)28<703:Tobtem>2.0.Co;2

DeVries, P. M. R., \& Meade, B. J. (2013). Earthquake cycle deformation in the Tibetan plateau with a weak mid-crustal layer. Journal of Geophysical Research: Solid Earth, 118(6), 3101-3111, doi:10.1002/jgrb.50209

Diao, F., Xiong, X., \& Wang, R. (2011). Mechanisms of Transient Postseismic Deformation Following the 2001 Mw 7.8 Kunlun (China) Earthquake. Pure and Applied Geophysics, 168(5), 767-779, doi: $10.1007 / \mathrm{s} 00024-010-0154-5$

Fan, G., \& Lay, T. (2002). Characteristics of Lg attenuation in the Tibetan Plateau. Journal of Geophysical Research: Solid Earth, 107(B10), ESE 14-11-ESE 14-15, doi:10.1029/2001jb000804

Fialko, Y. (2004). Evidence of fluid-filled upper crust from observations of postseismic deformation due to the 1992 Mw7.3 Landers earthquake. Journal of Geophysical Research: Solid Earth, 109(B8), doi:doi:10.1029/2004JB002985

Gan, W., Zhang, P., Shen, Z.-K., Niu, Z., Wang, M., Wan, Y., Zhou, D., \& Cheng, J. (2007). Present-day crustal motion within the Tibetan Plateau inferred from GPS measurements. Journal of Geophysical Research: Solid Earth, 112(B8), doi:10.1029/2005jb004120

Guo, J., Lin, A., Sun, G., \& Zheng, J. (2007). Surface Ruptures Associated with the 1937 M 7.5 Tuosuo Lake and the 1963 M 7.0 Alake Lake Earthquakes and the Paleoseismicity along the Tuosuo Lake Segment of the Kunlun Fault, Northern Tibet. Bulletin of the Seismological Society of America, 97(2), 474-496, doi:10.1785/0120050103

Haines, A. J., \& Holt, W. E. (1993). A procedure for obtaining the complete horizontal motions within zones of distributed deformation from the inversion of strain rate data. Journal of Geophysical Research: Solid Earth, 98(B7), 12057-12082, doi:10.1029/93jb00892

He, C., Wang, Z., \& Yao, W. (2007). Frictional sliding of gabbro gouge under hydrothermal conditions. Tectonophysics, 445(3), 353-362, doi:https://doi.org/10.1016/j.tecto.2007.09.008

He, P., Wang, M., Wang, Q., \& Shen, Z.-K. (2018). Rheological structure of lithosphere in northern Tibet inferred from postseismic deformation modeling of the 2001 Mw7.8 Kokoxili earthquake. Chinese Journal of Geophysics (in Chinese), 61(2), 531-544, doi:10.6038/cjg2018L0189

Hearn, E. H., Reilinger, R. E., \& Bürgmann, R. (2002). Dynamics of İzmit Earthquake Postseismic Deformation and Loading of the Düzce Earthquake Hypocenter. Bulletin of the Seismological Society of America, 
92(1), 172-193, doi:10.1785/0120000832

Henriquet, M., Avouac, J.-P., \& Bills, B. G. (2019). Crustal rheology of southern Tibet constrained from lakeinduced viscoelastic deformation. Earth and Planetary Science Letters, 506, 308-322, doi:https://doi.org/10.1016/j.eps1.2018.11.014

Herring, T., King, R., \& McCluskey, S. (2015). Introduction to GAMIT/GLOBK, release 10.4. Massachusetts Institute of Technology, Cambridge.

Hilley, G. E., Bürgmann, R., Zhang, P.-Z., \& Molnar, P. (2005). Bayesian inference of plastosphere viscosities near the Kunlun Fault, northern Tibet. Geophysical Research Letters, 32(1), doi:doi:10.1029/2004GL021658

Hilley, G. E., Johnson, K. M., Wang, M., Shen, Z.-K., \& Bürgmann, R. (2009). Earthquake-cycle deformation and fault slip rates in northern Tibet. Geology, 37(1), 31-34, doi:10.1130/g25157a.1

Karplus, M. S., Zhao, W., Klemperer, S. L., Wu, Z., Mechie, J., Shi, D., Brown, L., \& Chen, C. (2011). Injection of Tibetan crust beneath the south Qaidam Basin: Evidence from INDEPTH IV wide-angle seismic data. Journal of Geophysical Research: Solid Earth, 116(B7), doi:doi:10.1029/2010JB007911

Kenner, S. J., \& Segall, P. (2000). Postseismic deformation following the 1906 San Francisco earthquake. Journal of Geophysical Research: Solid Earth, 105(B6), 13195-13209, doi:10.1029/2000jb900076

Kirby, E., Harkins, N., Wang, E., Shi, X., Fan, C., \& Burbank, D. (2007). Slip rate gradients along the eastern Kunlun fault. Tectonics, 26(2), doi:10.1029/2006tc002033

Klinger, Y., Michel, R., \& King, G. C. P. (2006). Evidence for an earthquake barrier model from Mw 7.8 Kokoxili (Tibet) earthquake slip-distribution. Earth and Planetary Science Letters, 242(3), 354-364, doi:https://doi.org/10.1016/j.epsl.2005.12.003

Klinger, Y., Xu, X., Tapponnier, P., Van der Woerd, J. r., Lasserre, C., \& King, G. (2005). High-Resolution Satellite Imagery Mapping of the Surface Rupture and Slip Distribution of the Mw 7.8, 14 November 2001 Kokoxili Earthquake, Kunlun Fault, Northern Tibet, China. Bulletin of the Seismological Society of America, 95(5), 1970-1987, doi:10.1785/0120040233

Langbein, J. (2017). Improved efficiency of maximum likelihood analysis of time series with temporally correlated errors. Journal of Geodesy, 91(8), 985-994, doi:10.1007/s00190-017-1002-5

Lasserre, C., Peltzer, G., Crampé, F., Klinger, Y., Van der Woerd, J., \& Tapponnier, P. (2005). Coseismic deformation of the $2001 \mathrm{Mw}=7.8$ Kokoxili earthquake in Tibet, measured by synthetic aperture radar interferometry. Journal of Geophysical Research: Solid Earth, 110(B12), doi:10.1029/2004jb003500

Le Pape, F., Jones, A. G., Vozar, J., \& Wenbo, W. (2012). Penetration of crustal melt beyond the Kunlun Fault into northern Tibet. Nature Geoscience, 5, 330, doi:10.1038/ngeo1449

Li, H., Van der Woerd, J., Tapponnier, P., Klinger, Y., Qi, X., Yang, J., \& Zhu, Y. (2005). Slip rate on the Kunlun fault at Hongshui Gou, and recurrence time of great events comparable to the 14/11/2001, Mw 7.9 Kokoxili earthquake. Earth and Planetary Science Letters, 237(1), 285-299, doi:https://doi.org/10.1016/j.eps1.2005.05.041

Li, V. C., \& Rice, J. R. (1987). Crustal deformation in Great California earthquake cycles. Journal of Geophysical Research: Solid Earth, 92(B11), 11533-11551, doi:10.1029/JB092iB11p11533

Liang, S., Gan, W., Shen, C., Xiao, G., Liu, J., Chen, W., Ding, X., \& Zhou, D. (2013). Three-dimensional velocity field of present-day crustal motion of the Tibetan Plateau derived from GPS measurements. Journal of Geophysical Research: Solid Earth, 118(10), 5722-5732, doi:doi:10.1002/2013JB010503

Lisowski, M., Savage, J. C., \& Prescott, W. H. (1991). The velocity field along the San Andreas Fault in central and southern California. Journal of Geophysical Research: Solid Earth, 96(B5), 8369-8389, doi:10.1029/91jb00199

Liu, S., Shen, Z.-K., \& Bürgmann, R. (2015). Recovery of secular deformation field of Mojave Shear Zone in Southern California from historical terrestrial and GPS measurements. Journal of Geophysical Research: Solid Earth, 120(5), 3965-3990, doi:doi:10.1002/2015JB011941

Loveless, J. P., \& Meade, B. J. (2011). Partitioning of localized and diffuse deformation in the Tibetan Plateau from joint inversions of geologic and geodetic observations. Earth and Planetary Science Letters, 303(1), 11-24, doi:https://doi.org/10.1016/j.epsl.2010.12.014

Meade, B. J. (2007). Present-day kinematics at the India-Asia collision zone. Geology, 35(1), 81-84, doi:10.1130/g22924a.1

Meyer, B., Tapponnier, P., Bourjot, L., Métivier, F., Gaudemer, Y., Peltzer, G., Guo, S., \& Chen, Z. (1998). Crustal thickening in Gansu-Qinghai, lithospheric mantle subduction, and oblique, strike-slip controlled growth of the Tibet plateau. Geophysical Journal International, 135(1), 1-47, doi:10.1046/j.1365-246X.1998.00567.X

Owens, T. J., \& Zandt, G. (1997). Implications of crustal property variations for models of Tibetan plateau evolution. Nature, 387(6628), 37-43, doi:10.1038/387037a0

Peltzer, G., Rosen, P., Rogez, F., \& Hudnut, K. (1998). Poroelastic rebound along the Landers 1992 earthquake surface rupture. Journal of Geophysical Research: Solid Earth, 103(B12), 30131-30145, 
doi:doi:10.1029/98JB02302

Pollitz, F. F. (1997). Gravitational viscoelastic postseismic relaxation on a layered spherical Earth. Journal of Geophysical Research: Solid Earth, 102(B8), 17921-17941, doi:doi:10.1029/97JB01277

Pollitz, F. F., Wicks, C., \& Thatcher, W. (2001). Mantle Flow Beneath a Continental Strike-Slip Fault: Postseismic Deformation After the 1999 Hector Mine Earthquake. Science, 293(5536), 1814-1818, doi:10.1126/science.1061361

Ren, J., \& Wang, M. (2005). GPS measured crustal deformation of the Ms 8.1 Kunlun earthquake on November 14th 2001 in Qinghai-Xizang plateau. Quat. Sci, 25, 34-44,

Rippe, D., \& Unsworth, M. (2010). Quantifying crustal flow in Tibet with magnetotelluric data. Physics of the Earth and Planetary Interiors, 179(3), 107-121, doi:https://doi.org/10.1016/j.pepi.2010.01.009

Rodgers, A. J., \& Schwartz, S. Y. (1998). Lithospheric structure of the Qiangtang Terrane, northern Tibetan Plateau, from complete regional waveform modeling: Evidence for partial melt. Journal of Geophysical Research: Solid Earth, 103(B4), 7137-7152, doi:10.1029/97jb03535

Royden, L. H., Burchfiel, B. C., King, R. W., Wang, E., Chen, Z., Shen, F., \& Liu, Y. (1997). Surface Deformation and Lower Crustal Flow in Eastern Tibet. Science, 276(5313), 788-790, doi:10.1126/science.276.5313.788

Ryder, I., Bürgmann, R., \& Pollitz, F. (2011). Lower crustal relaxation beneath the Tibetan Plateau and Qaidam Basin following the 2001 Kokoxili earthquake. Geophysical Journal International, 187(2), 613-630, doi:10.1111/j.1365-246X.2011.05179.x

Savage, J. C., \& Burford, R. O. (1973). Geodetic determination of relative plate motion in central California. Journal of Geophysical Research (1896-1977), 78(5), 832-845, doi:10.1029/JB078i005p00832

Savage, J. C., \& Svarc, J. L. (2009). Postseismic relaxation following the 1992 M7.3 Landers and 1999 M7.1 Hector Mine earthquakes, southern California. Journal of Geophysical Research: Solid Earth, 114(B1), doi:doi:10.1029/2008JB005938

Shao, Z., Fu, R., Xue, T., \& Huang, J. (2008). Numerical Simulation and Discussion on the Mechanism of Postseismic Deformation After Kunlun Ms8.1 Earthquake. Chinese Journal of Geophysics, 51(3), 584596, doi:10.1002/cjg2.1248

Shapiro, N. M., Ritzwoller, M. H., Molnar, P., \& Levin, V. (2004). Thinning and Flow of Tibetan Crust Constrained by Seismic Anisotropy. Science, 305(5681), 233-236, doi:10.1126/science.1098276

Shen, Z.-K., Jackson, D. D., Feng, Y., Cline, M., Kim, M., Fang, P., \& Bock, Y. (1994). Postseismic deformation following the Landers earthquake, California, 28 June 1992. Bulletin of the Seismological Society of America, 84(3), 780-791,

Shen, Z.-K., Jackson, D. D., \& Ge, B. X. (1996). Crustal deformation across and beyond the Los Angeles basin from geodetic measurements. Journal Of Geophysical Research, 101(B12), 27957-27980, doi:10.1029/96jb02544

Shen, Z. K., Wang, M., Zeng, Y., \& Wang, F. (2015). Optimal Interpolation of Spatially Discretized Geodetic Data. Bulletin Of The Seismological Society Of America, doi:10.1785/0120140247

Tapponnier, P., Xu, Z., Roger, F., Meyer, B., Arnaud, N., Wittlinger, G., \& Yang, J. (2001). Oblique Stepwise Rise and Growth of the Tibet Plateau. Science, 294(5547), 1671-1677, doi:10.1126/science.105978

Thatcher, W. (1983). Nonlinear strain buildup and the earthquake cycle on the San Andreas Fault. Journal of Geophysical Research: Solid Earth, 88(B7), 5893-5902, doi:10.1029/JB088iB07p05893

Thatcher, W. (2007). Microplate model for the present-day deformation of Tibet. Journal of Geophysical Research: Solid Earth, 112(B1), doi:10.1029/2005jb004244

Tocheport, A., Rivera, L., \& Van der Woerd, J. r. m. (2006). A Study of the 14 November 2001 Kokoxili Earthquake: History and Geometry of the Rupture from Teleseismic Data and Field Observations. Bulletin of the Seismological Society of America, 96(5), 1729-1741, doi:10.1785/0120050200

Unsworth, M., Wenbo, W., Jones, A. G., Li, S., Bedrosian, P., Booker, J., Deng, M., \& Tan, H. (2004). Crustal and upper mantle structure of northern Tibet imaged with magnetotelluric data. Journal of Geophysical Research: Solid Earth, 109(B2), doi:doi:10.1029/2002JB002305

Van der Woerd, J., Ryerson, F. J., Tapponnier, P., Gaudemer, Y., Finkel, R., Meriaux, A. S., Caffee, M., Zhao, G., \& He, Q. (1998). Holocene left-slip rate determined by cosmogenic surface dating on the Xidatan segment of the Kunlun fault (Qinghai, China). Geology, 26(8), 695-698, doi:10.1130/00917613(1998)026<0695:Hlsrdb>2.3.Co;2

Van Der Woerd, J., Tapponnier, P., Ryerson, F. J., Meriaux, A.-S., Meyer, B., Gaudemer, Y., Zhao, G., \& Xu, Z. (2002). Uniform postglacial slip-rate along the central $600 \mathrm{~km}$ of the Kunlun Fault (Tibet), from $26 \mathrm{Al}, 10 \mathrm{Be}$, and $14 \mathrm{C}$ dating of riser offsets, and climatic origin of the regional morphology. Geophysical Journal International, 148(3), 356-388, doi:doi:10.1046/j.1365-246x.2002.01556.x

Vergne, J., Wittlinger, G., Hui, Q., Tapponnier, P., Poupinet, G., Mei, J., Herquel, G., \& Paul, A. (2002). Seismic evidence for stepwise thickening of the crust across the NE Tibetan plateau. Earth and Planetary Science Letters, 203(1), 25-33, doi:https://doi.org/10.1016/S0012-821X(02)00853-1 
Vergnolle, M., Pollitz, F., \& Calais, E. (2003). Constraints on the viscosity of the continental crust and mantle from GPS measurements and postseismic deformation models in western Mongolia. Journal of Geophysical Research: Solid Earth, 108(B10), doi:10.1029/2002jb002374

Wan, Y.-G., Shen, Z.-K., Wang, M., Zhang, Z.-S., Gan, W.-J., Wang, Q.-L., \& Sheng, S.-Z. (2008). Coseismic Slip Distribution of the 2001 Kunlun Mountain Pass West Earthquake Constrained by GPS and Insar Data. Chinese Journal of Geophysics, 51(4), 753-764, doi:10.1002/cjg2.1268

Wang, M., Shen, Z.-K., Chen, J., Zhang, Z., Wang, Q.-L., \& Gan, W. (2003). Slip distribution of the 2001 Mw 7.8 Kokoxili earthquake, western China. Paper presented at the EGS-AGU-EUG Joint Assembly.

Wang, M., Shen, Z., Niu, Z., Zhang, Z., Sun, H., Gan, W., Wang, Q., \& Ren, Q. (2003). Contemporary crustal deformation of the Chinese continent and tectonic block model. Science in China Series D: Earth Sciences, 46(2), 25-40, doi:10.1360/03dz0003

Wang, Q., Zhang, P.-Z., Freymueller, J. T., Bilham, R., Larson, K. M., Lai, X., You, X., Niu, Z., Wu, J., Li, Y., Liu, J., Yang, Z., \& Chen, Q. (2001). Present-Day Crustal Deformation in China Constrained by Global Positioning System Measurements. Science, 294(5542), 574-577, doi:10.1126/science.1063647

Wang, R., Lorenzo-Martín, F., \& Roth, F. (2006). PSGRN/PSCMP--a new code for calculating co- and postseismic deformation, geoid and gravity changes based on the viscoelastic-gravitational dislocation theory. Computers \& Geosciences, 32(4), 527-541, doi:DOI: 10.1016/j.cageo.2005.08.006

Wei, S., Chen, Y. J., Sandvol, E., Zhou, S., Yue, H., Jin, G., Hearn, T., Jiang, M., Wang, H., Fan, W., Liu, Z., Ge, Z., Wang, Y., Feng, Y., \& Ni, J. (2010). Regional earthquakes in northern Tibetan Plateau: Implications for lithospheric strength in Tibet. Geophysical Research Letters, 37(19), doi:10.1029/2010gl044800

Wei, W., Unsworth, M., Jones, A., Booker, J., Tan, H., Nelson, D., Chen, L., Li, S., Solon, K., Bedrosian, P., Jin, S., Deng, M., Ledo, J., Kay, D., \& Roberts, B. (2001). Detection of Widespread Fluids in the Tibetan Crust by Magnetotelluric Studies. Science, 292(5517), 716-719, doi:10.1126/science.1010580

Wen, X., Yi, G., \& Xu, X. (2007). Background and precursory seismicities along and surrounding the Kunlun fault before the Ms8.1, 2001, Kokoxili earthquake, China. Journal of Asian Earth Sciences, 30(1), 6372, doi:https://doi.org/10.1016/j.jseaes.2006.07.008

Wen, Y., Li, Z., Xu, C., Ryder, I., \& Bürgmann, R. (2012). Postseismic motion after the 2001 MW 7.8 Kokoxili earthquake in Tibet observed by InSAR time series. Journal of Geophysical Research: Solid Earth, 117(B8), doi:10.1029/2011jb009043

Wessel, P., \& Smith, W. H. (1998). New, improved version of Generic Mapping Tools released. Eos, Transactions American Geophysical Union, 79(47), 579-579,

Xu, X., Chen, W., Ma, W., Yu, G., \& Chen, G. (2002). Surface Rupture of the Kunlunshan Earthquake (Ms 8.1), Northern Tibetan Plateau, China. Seismological Research Letters, 73(6), 884-892, doi:10.1785/gssrl.73.6.884

Xu, X., Yu, G., Klinger, Y., Tapponnier, P., \& Van Der Woerd, J. (2006). Reevaluation of surface rupture parameters and faulting segmentation of the 2001 Kunlunshan earthquake (Mw7.8), northern Tibetan Plateau, China. Journal of Geophysical Research: Solid Earth, 111(B5), doi:10.1029/2004jb003488

Yang, Y., Ritzwoller, M. H., Zheng, Y., Shen, W., Levshin, A. L., \& Xie, Z. (2012). A synoptic view of the distribution and connectivity of the mid-crustal low velocity zone beneath Tibet. Journal of Geophysical Research: Solid Earth, 117(B4), doi:10.1029/2011jb008810

Yin, A., Dang, Y., Zhang, M., McRivette, M. W., Burgess, W. P., \& Chen, X. (2007). Cenozoic tectonic evolution of Qaidam basin and its surrounding regions (part 2): Wedge tectonics in southern Qaidam basin and the Eastern Kunlun Range. In J. W. Sears, T. A. Harms, \& C. A. Evenchick (Eds.), (Vol. 433, pp. 0): Geological Society of America.

Yin, A., \& Harrison, T. M. (2000). Geologic Evolution of the Himalayan-Tibetan Orogen. Annual Review of Earth and Planetary Sciences, 28(1), 211-280, doi:10.1146/annurev.earth.28.1.211

Zhang, P.-Z., Shen, Z., Wang, M., Gan, W., Bürgmann, R., Molnar, P., Wang, Q., Wu, J., Sun, J., Sun, H., You, X., \& Niu, Z. (2004). Continuous deformation of the Tibetan Plateau from global positioning system data. Geology, 32(9), 809-812, doi:10.1130/g20554.1

Zhang, Z., McCaffrey, R., \& Zhang, P. (2013). Relative motion across the eastern Tibetan plateau: Contributions from faulting, internal strain and rotation rates. Tectonophysics, 584, 240-256, doi:https://doi.org/10.1016/j.tecto.2012.08.006

Zhao, D., Qu, C., Shan, X., Bürgmann, R., Gong, W., \& Zhang, G. (2018). Spatiotemporal Evolution of Postseismic Deformation Following the 2001 Mw7.8 Kokoxili, China, Earthquake from 7 Years of Insar Observations. Remote Sensing, 10(12), 1988,

Zheng, G., Wang, H., Wright, T. J., Lou, Y., Zhang, R., Zhang, W., Shi, C., Huang, J., \& Wei, N. (2017). Crustal Deformation in the India-Eurasia Collision Zone From 25 Years of GPS Measurements. Journal of Geophysical Research: Solid Earth, 122(11), 9290-9312, doi:10.1002/2017jb014465

Zhu, L., \& Helmberger, D. V. (1998). Moho Offset Across the Northern Margin of the Tibetan Plateau. Science, 281(5380), 1170-1172, doi:10.1126/science.281.5380.1170 
Table 1. GPS velocities for the period 2007-2015 in a Eurasia-fixed reference frame

\begin{tabular}{|c|c|c|c|c|c|c|c|c|c|}
\hline Site & Lon $\left({ }^{\circ}\right)$ & Lat $\left({ }^{\circ}\right)$ & $\mathrm{V}_{\mathrm{E}^{\mathrm{a}}}$ & $\mathrm{V}_{\mathrm{N}^{\mathrm{a}}}$ & $\sigma_{\mathrm{E}}$ & $\sigma_{\mathrm{N}}$ & corr & VE_pre $^{a}$ & $\mathrm{~V}_{\mathrm{N} \_p r e}{ }^{\mathrm{a}}$ \\
\hline TXSI & 5.645 & 37.469 & 7.9 & 5.6 & 0.67 & 0.69 & 0.101 & $9.1(7.6-10.0)$ & $5.4(5.3-5.6)$ \\
\hline NSNK & 4.804 & 36.200 & 7.6 & 6.6 & 0.64 & 0.68 & 0.062 & $10.0(8.5-10.9)$ & $6.3(6.1-6.5)$ \\
\hline $\mathrm{QHC}$ & 94.772 & 36.145 & 8.0 & 7.0 & 0.75 & 0.77 & 0.045 & $10.2(8.7-11.1)$ & $6.7(6.6-6.9)$ \\
\hline XGGU & 4.795 & 36.062 & 7.7 & 7.2 & 0.64 & 0.66 & 0.057 & $10.3(8.8-11.2)$ & $6.8(6.7-7.0)$ \\
\hline SCHK & 94.348 & 35.853 & 7.9 & 7.5 & 0.64 & 0.67 & 0.044 & $11.1(9.2-11.7)$ & $7.0(7.0-7.3)$ \\
\hline XDTN & 4.337 & 35.764 & 9.2 & 7.7 & 0.64 & 0.67 & 0.039 & $11.8(9.8-12.4)$ & $7.3(7.3-7.6)$ \\
\hline $\operatorname{DDTN}^{c}$ & 544 & 35.742 & 15.2 & 15.6 & 4.40 & 4.28 & 0.001 & $13.0(11.0-13.5)$ & $15.9(15.8-16.2)$ \\
\hline HCGU & 4.936 & 35.734 & 10.7 & 7.2 & 0.69 & 0.72 & 0.037 & $11.4(9.5-12.0)$ & $7.1(7.0-7.4)$ \\
\hline WENQ & 95.262 & 35.734 & 11.7 & 7.3 & 0.79 & 0.79 & 0.030 & $11.2(9.3-11.8)$ & $7.4(7.3-7.6)$ \\
\hline YZSE & 94.284 & 35.561 & 21.1 & 4.7 & 0.65 & 0.68 & 0.027 & $13.9(13.3-16.7)$ & $5.7(5.3-5.8)$ \\
\hline DUOX & 94.132 & 35.054 & 23.4 & 3.7 & 0.67 & 0.69 & -0.001 & $15.8(14.8-18.6)$ & $4.8(4.4-4.9)$ \\
\hline FHSN & 92.919 & 34.663 & 21.6 & 8.1 & 1.05 & 1.20 & -0.017 & $17.9(16.4-19.9)$ & $8.6(8.4-8.8)$ \\
\hline QHTT $^{\mathbf{b}}$ & 92.438 & 34.217 & 18.7 & 9.1 & 0.84 & 0.97 & -0.050 & $20.4(18.7-22.9)$ & $8.9(8.5-9.1)$ \\
\hline
\end{tabular}

a The velocities in the fourth and fifth columns, respectively ( $V_{E}$, east-directed velocity) and $\left(V_{N}\right.$, north-directed velocity), have contributions from both secular motions and postseismic transients. The pre-Kokoxili velocities ( $\mathrm{mm} / \mathrm{yr}$ ) are in the last two columns (see section 3 ). Shown in the parentheses are the rates in the $70 \%$ confidence level.

b CMONOC sites whose data have been analyzed together with our Xidatan cGPS observations, using GAMIT/GLOBK.

c DDTN site only had a few months of data and is not used in the subsequent analysis. 
Table 2. GPS datasets used in this study

\begin{tabular}{llll}
\hline Name & Time & Type & References \\
\hline CMONOC-I & 1994-2001 & Campaign GPS & (Wang et al., 2003b; Zhang et al., 2004) \\
\hline CMONOC-II & $2009-2015$ & Campaign GPS & (Zheng et al., 2017) \\
\hline QZ profile & Dec. 2001- Nov. 2002 & Campaign|Continuous GPS & (Ren \& Wang, 2005) \\
\hline & & & \\
\hline & & & \\
\hline
\end{tabular}


Table 3. Model fit to the data (Weighted residual sum of squares)

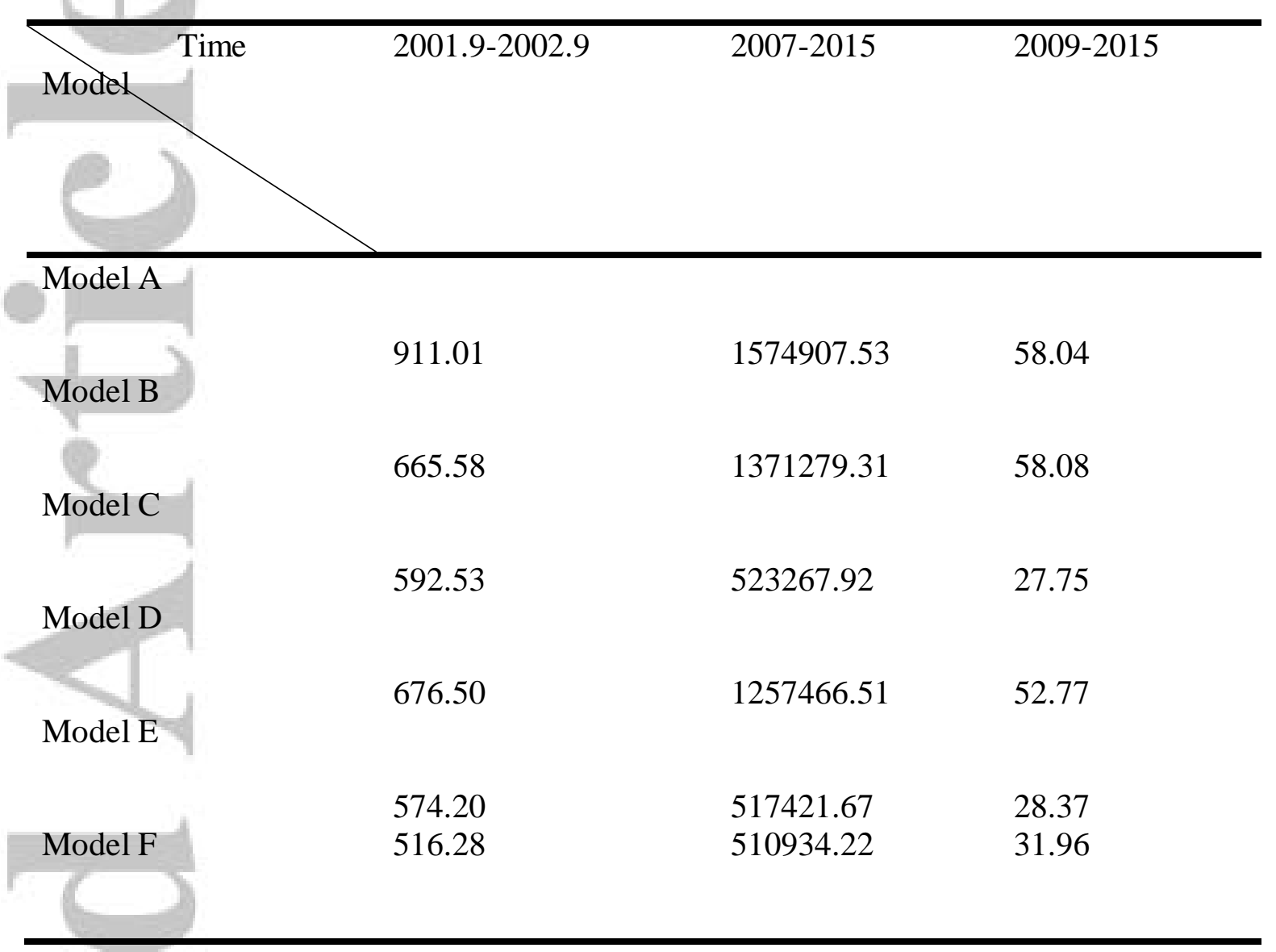


Table 4. Optimal viscosities (Maxwell rheology)

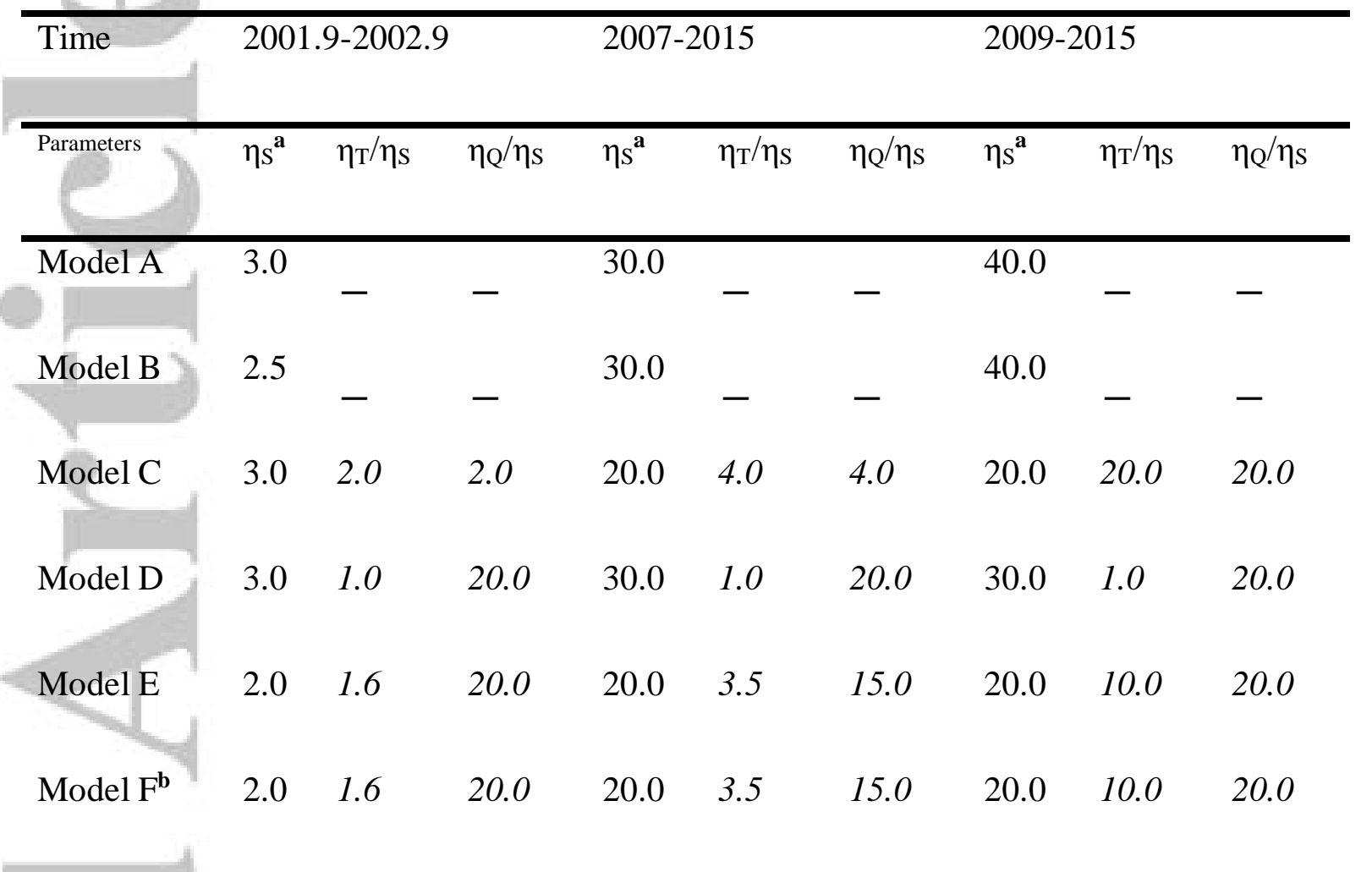

a Unit: $1 \mathrm{EPa} \mathrm{s}=1.0 \times 10^{18} \mathrm{~Pa} \mathrm{~s}$. The parameters $\eta_{S}, \eta_{Q}$, and $\eta_{T}$ are the Maxwell viscosity of the LC beneath the Songpan-Ganzi terrane, Qaidam Basin, and the transition zone in between, respectively.

b Transient and steady LC viscosities beneath the Qiangtang are $4.0 \times 10^{17} \mathrm{~Pa} \mathrm{~s}$ and $2.0 \times 10^{19} \mathrm{~Pa}$ s, respectively. 


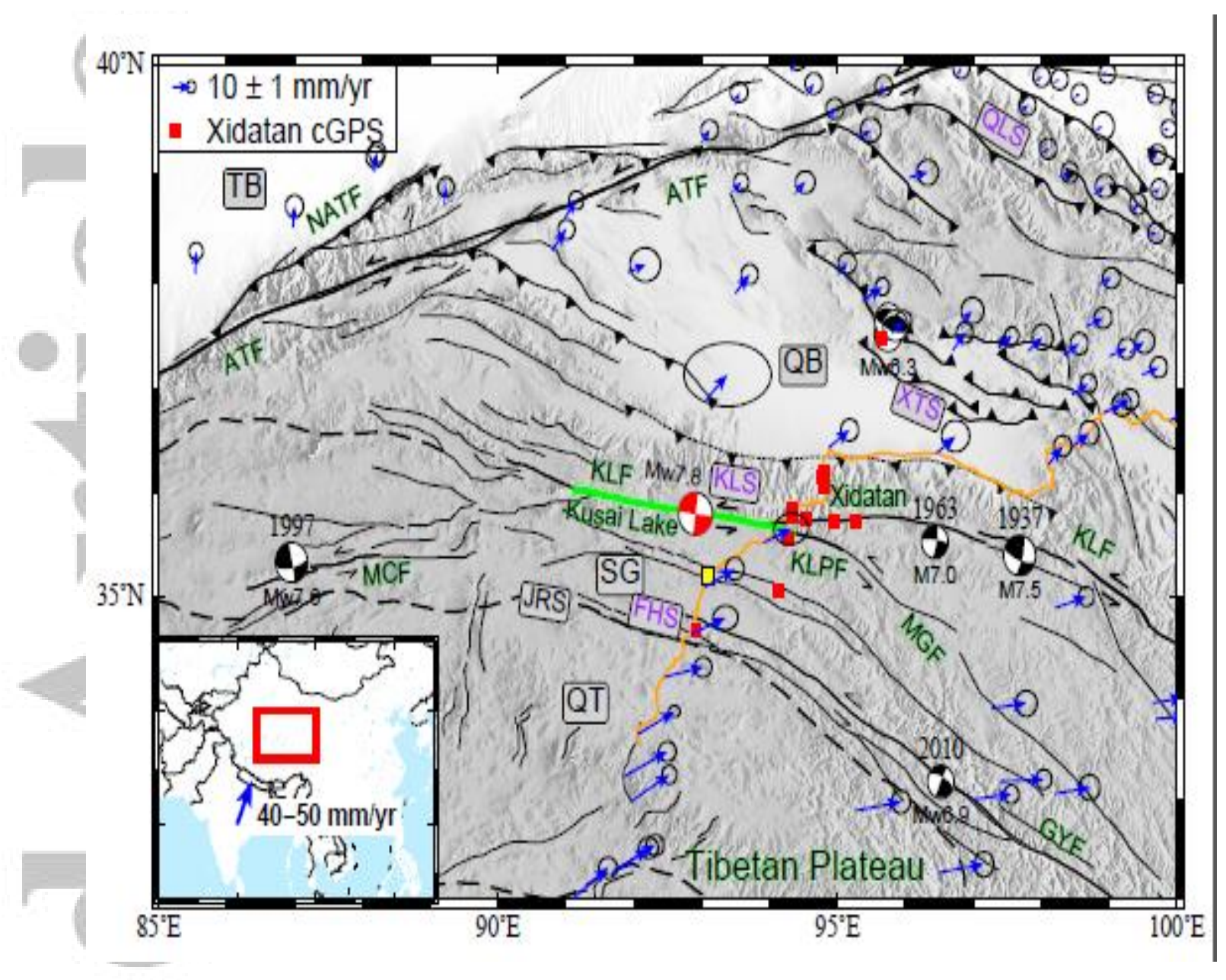

Figure 1. Tectonic setting of the northern Tibetan Plateau. The red (compressional quadrant) and black beach balls indicate the focal mechanisms for the 2001 Mw7.8 Kokoxili and other moderate-sized and large earthquakes, respectively. Red squares represent the Xidatan GPS sites installed since 2007-2009. The pre-Kokoxili CMONOC-I GPS velocities (19982001) relative to the stable Eurasia are shown by blue vectors tipped with $95 \%$ confidence error ellipses. Green thick line shows the mapped surface trace of coseismic rupture. Orange line indicates the Qingzand Road. The yellow square indicates the location of Wudaoliang. Dash lines represent the suture zone (e.g., JRS=Jinsha River suture zone). Geological regions are abbreviated as: QT=Qiangtang terrane; $\mathrm{SG}=$ Songpan-Ganzi terrane; $\mathrm{QB}=$ Qaidam Basin; TB=Tarim Basin. Mountains are abbreviated as: FHS=Fenghuo Shan; KLS=Kunlun Shan; XTS=Xitie Shan; QLS=Qilian Shan. Faults in the region are abbreviated as:KLF=Kunlun fault, KLPF=Kunlun Pass fault, ATF=AltynTagh fault, GYF=Ganzi-Yushu fault, NATF=Northern AltynTagh fault, MCF=MargaiCaka fault, and MGF=Maduo-Gande fault. The studying area is outlined by the red rectangle in the lower left plot in which a $\sim 40-$ $50 \mathrm{~mm} / \mathrm{yr}$ northeast-directed blue vector indicates the rate of India-Asia collision. 

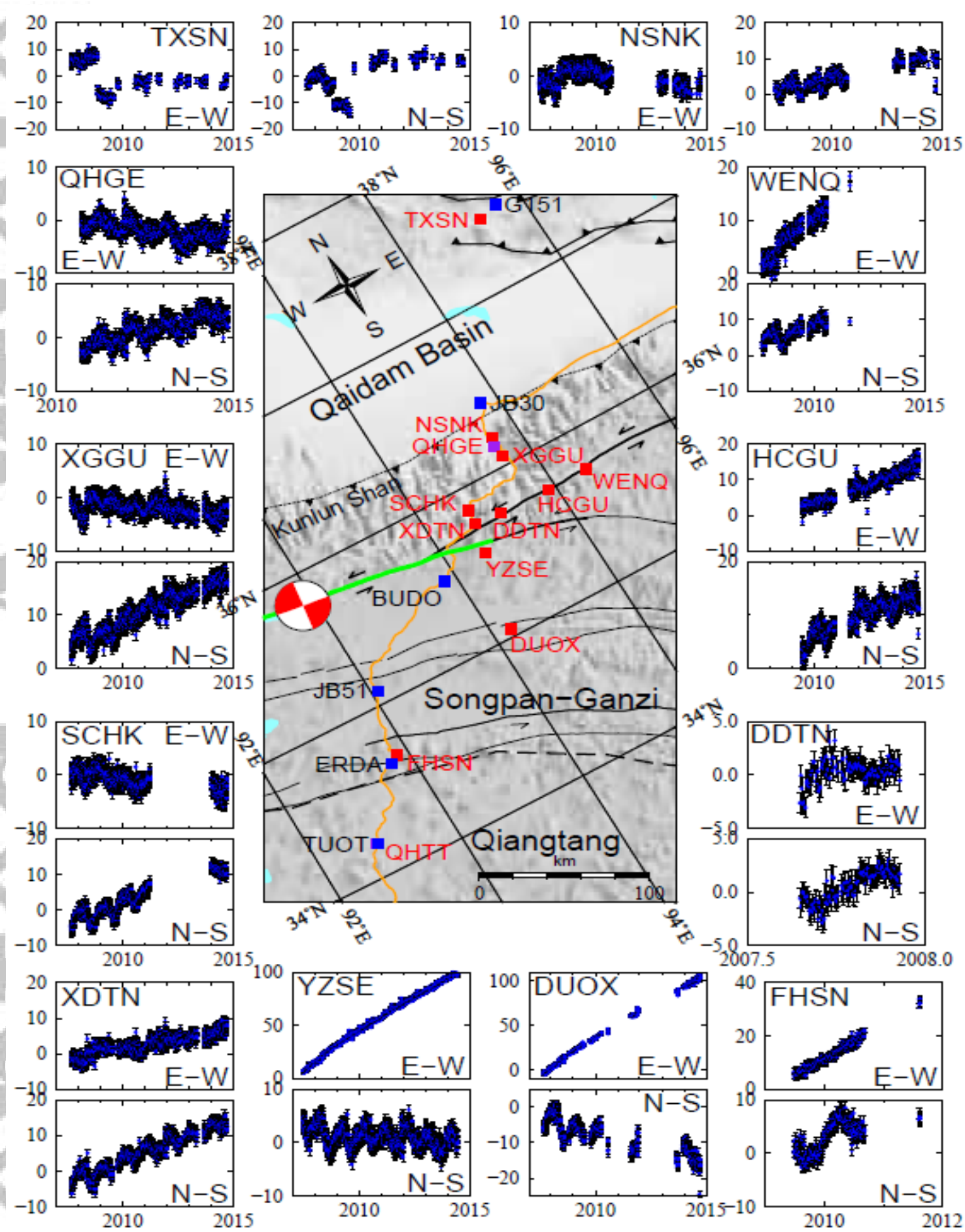

Figure 2. cGPS measurements along the Xidatan profile. The figure in the middle shows the geographic distribution of Xidatan GPS sites (red squares), CMONOC-I GPS sites (blue squares), coseismic rupture of the 2001 event (green line), and the Kunlun fault (thick black line). The surrounding subplots show the GPS position time series relative to the Qaidam Basin. 


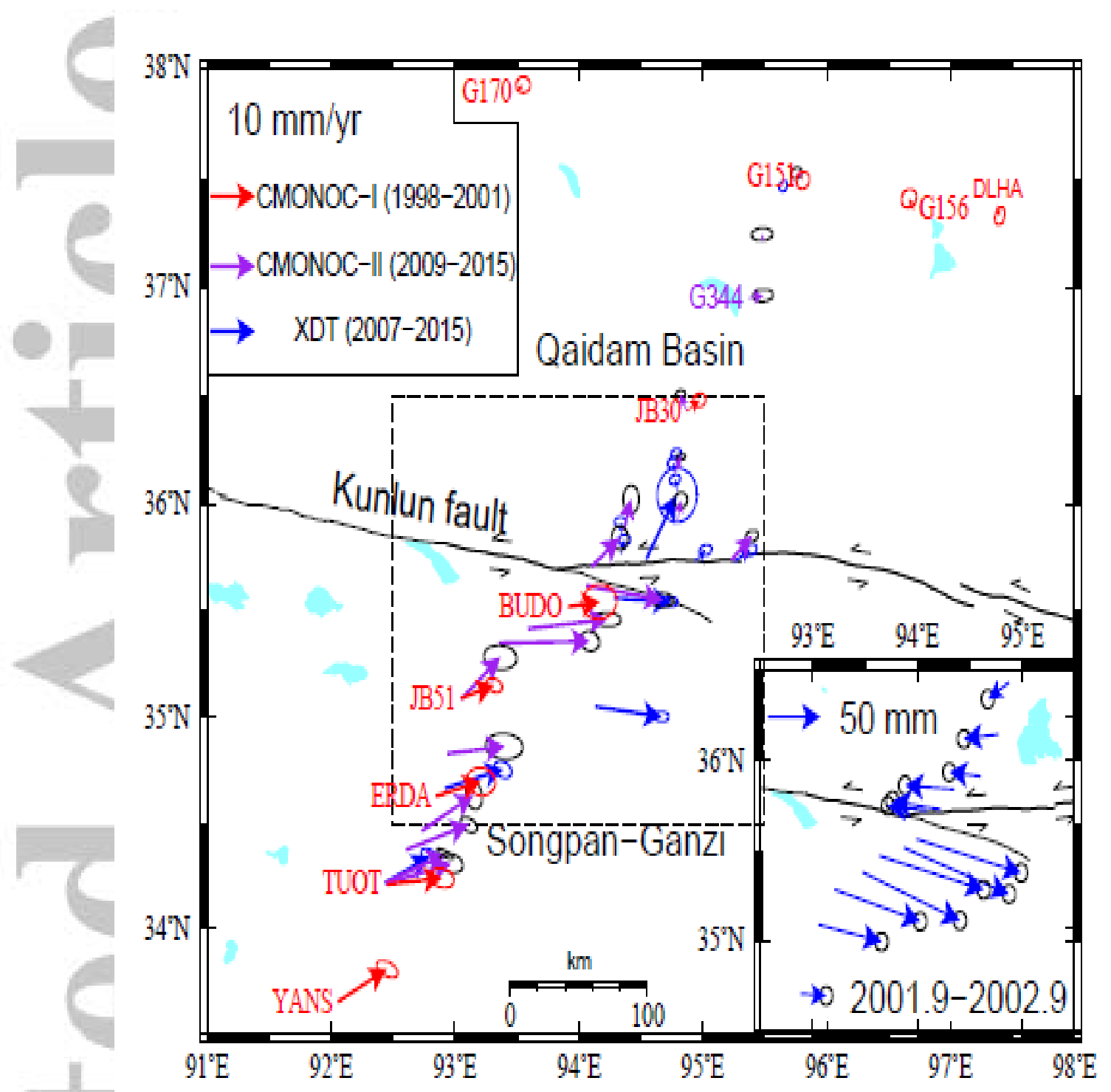

Figure 3. Map showing the 1998-2001 CMONOC-I (red vectors), 2009-2015 CMONOC-II (purple vectors) and 2007-2015 Xidatan (blue vectors) GPS velocities as well as 2001.92002.9 post-Kokoxili displacements (blue vectors in the lower right sub-figure whose boundary is shown by dashed line in the main figure) in the area adjacent to the Xidatan segment of the Kunlun fault. Vectors tipped with $39.3 \%$ confidence error ellipses in the main figure indicate the motion of the GPS sites relative to the Qaidam Basin. GPS velocities at two CMONOC sites (QHGE and QHTT) are plotted using the same color as our Xidatan cGPS velocities (also the same in Figure 4), as raw data of those two sites are processed together using GAMIT/GLOBK in this study. 


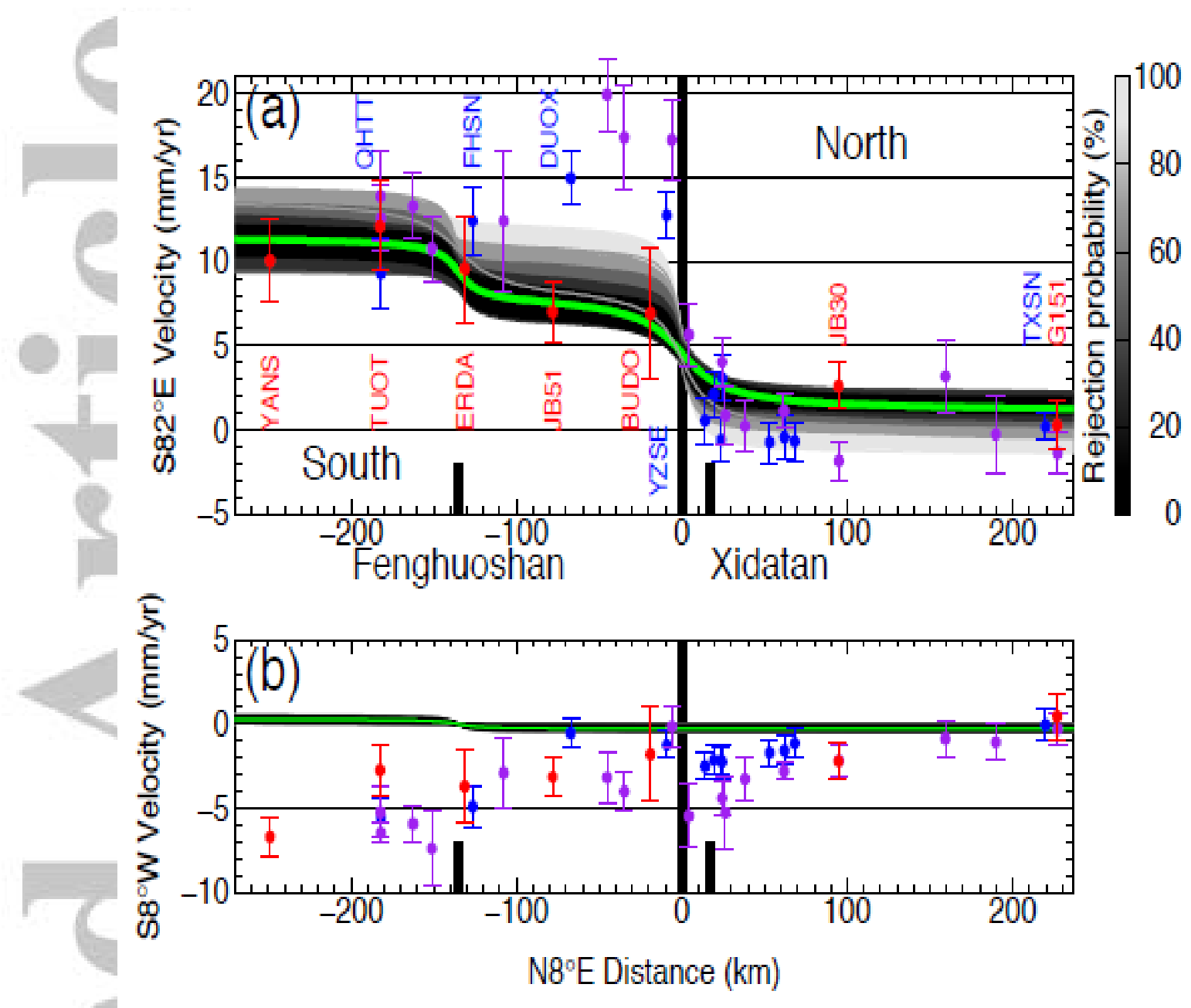

Figure 4. Pre-Kokoxili CMONOC-I (red dots), post-Kokoxili CMONOC-II (purple dots), and Xidatan (blue dots) GPS velocities versus perpendicular distance from the Kunlun fault. (a) Fault-parallel component. (b) Fault-perpendicular component. The azimuth of the fault is taken to be $S 82^{\circ} \mathrm{E}$. The green curves are model prediction from an optimum $2 \mathrm{D}$ dislocation model (see section 3.2), and the other curves are color-coded according to the probability. Error bars are one standard deviations on either side of the data points (after two steps of reference transformation, the 1-sigma uncertainties of the $S 82^{\circ} \mathrm{E}$ directed velocities are amplified by a factor of about two, to $\sim 0.8-2.0 \mathrm{~mm} / \mathrm{yr}$ for our Xidatan data and $1.5-3.9 \mathrm{~mm} / \mathrm{yr}$ for CMONOC-I data, respectively). The short black vertical line at $17.4 \mathrm{~km}$ and $-135.2 \mathrm{~km}$ indicate the positions of the Xidatan segment of the Kunlun fault and Fenghuoshan segment of the Ganzi-Yushu fault, respectively. The red and blue characters represent site names of the CMONOC-I and Xidatan GPS sites, respectively. 

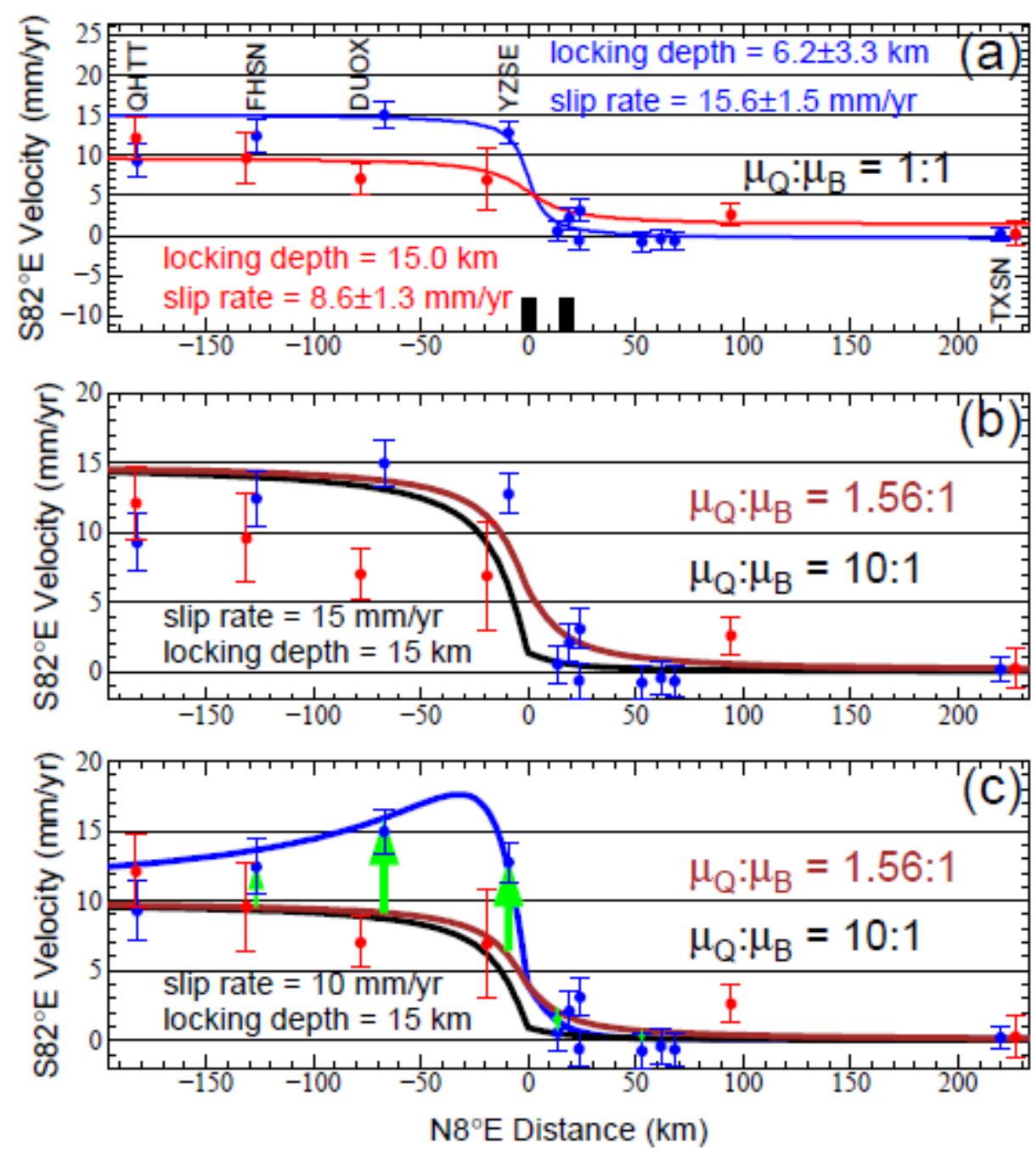

Figure 5. Surface deformation predicted from 2D dislocation models with shear modulus contrast across the fault ( $\mu_{\mathrm{B}}$ and $\mu_{\mathrm{Q}}$ are the shear modulus for the Songpan-Ganzi terrane and Qaidam Basin, respectively). As a reference, the case for homogeneous shear modulus is shown in subplot (a). Red and blue lines indicate the model fit to the pre- and post-Kokoxili data, respectively. Colored characters represent the values of the parameters. The strike-slip rates in subplots (b) and (c) are $15 \mathrm{~mm} / \mathrm{yr}$ and $10 \mathrm{~mm} / \mathrm{yr}$, respectively. Brown and black lines in subplots (b) and (c) indicate the cases for the ratio of shear modulus contrast being 1.56 and 10, respectively. The green vectors in subplot (c) schematically illustrate the potential postseismic transients. The blue curve is a model prediction of interseismic deformation (due to creeping at $10 \mathrm{~mm} / \mathrm{yr}$ below $15 \mathrm{~km}$ ) plus postseismic deformation (due to $70 \mathrm{~mm} / \mathrm{yr}$ afterslip at 15-65 km depth, with the ratio of shear modulus contrast being 5 to get more deformation to the south of the fault). 


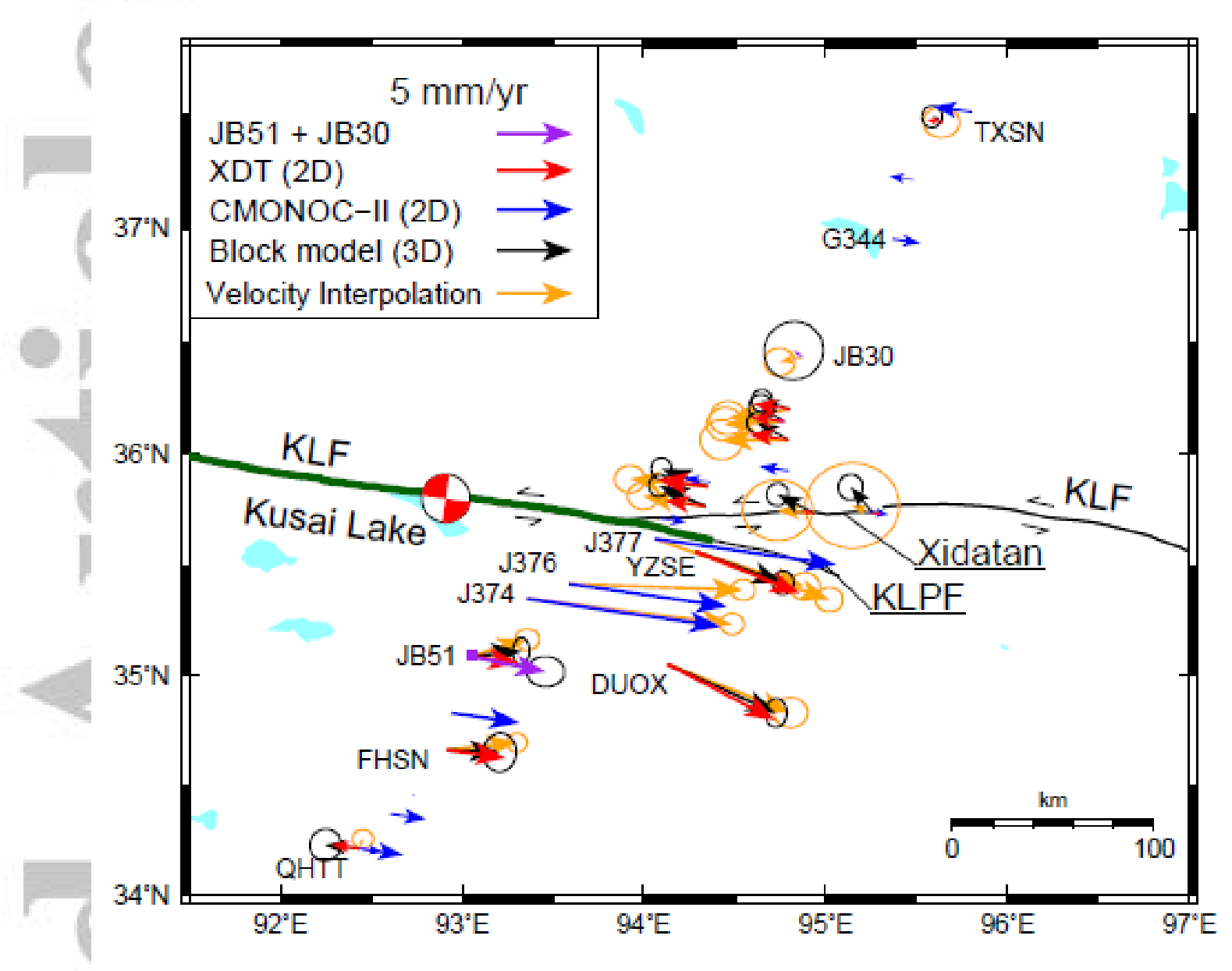

Figure 6. Map view of the postseismic transients in the post-Kokoxili GPS velocities derived by different methods $\left(v_{1}-v_{2}\right.$, in which $v_{1}$ is derived from post-Kokoxili GPS data and $v_{2}$ is derived from different methods). Purple vectors represent the benchmark postseismic transients at JB30 and JB51. Blue and red vectors for postseismic transients at CMONOC-II and Xidatan GPS sites, respectively, are obtained from 2D dislocation model (Text S5). The fault-normal motion correction has been made at DUOX and YZSE. Black and orange vectors show postseismic transients derived using 3D elastic block model (Text S6) and velocity interpolation (observed minus model predictions), respectively. Error ellipses are at the $39.3 \%$ confidence level. The focal mechanism for the 2001 event is from Tocheport et al., (2006). Dark green thick line shows the mapped surface trace of the 2001 rupture. 

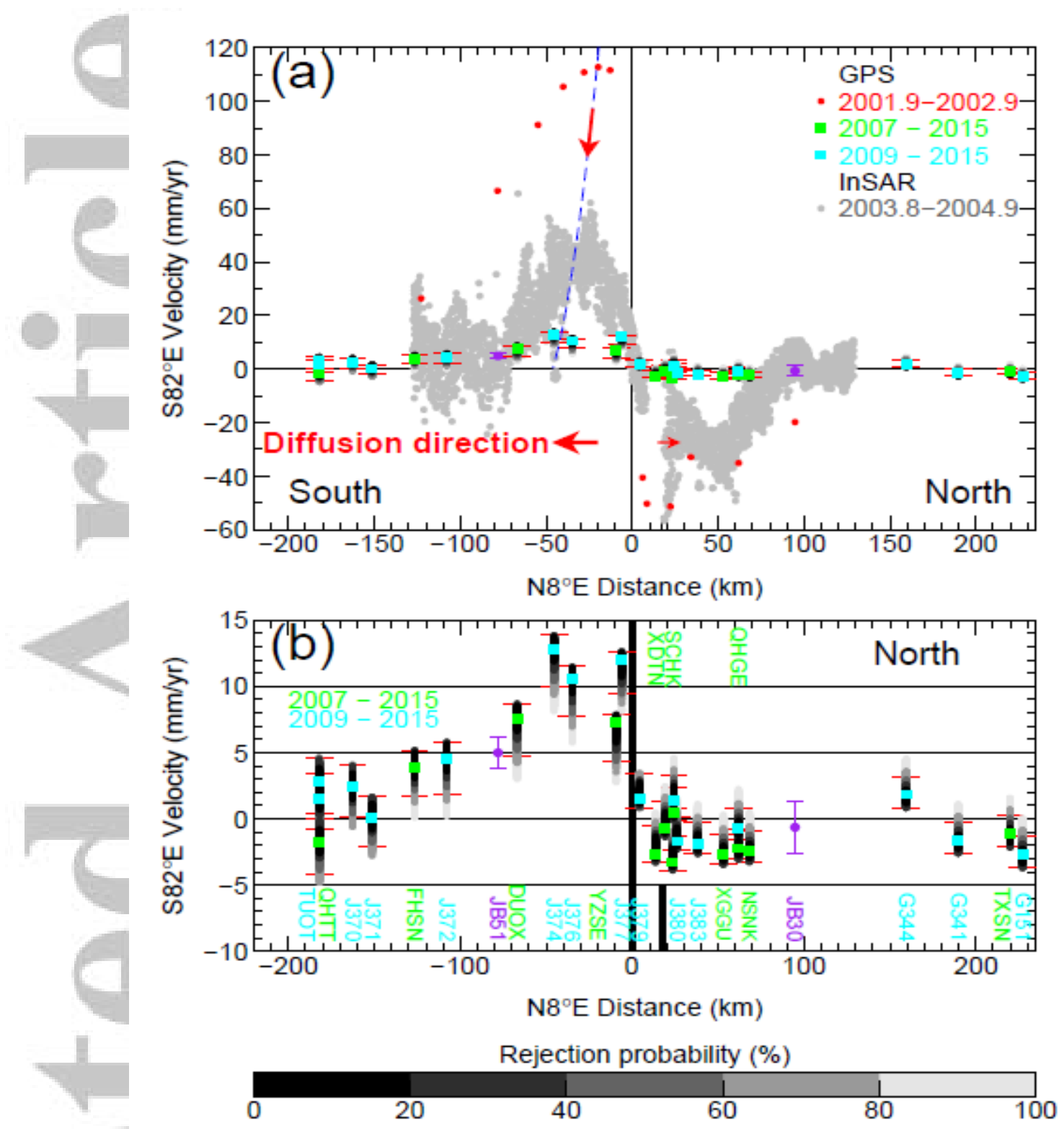

Figure 7. Fault-parallel postseismic transients versus perpendicular distance from the 2001 rupture. (a) A compilation of postseismic transients from December 2001 to 2015 as measured by GPS and InSAR. (b) Close-up view of the postseismic transients during the time period from 2007/2009 to 2015. The red horizontal vectors heading away from the fault (ZERO distance) and red vector along the blue dash line illustrate how postseismic transients diffuse and decay with time (from 2001.9-2002.9 to 2007/2009-2015), respectively. Cyan and green squares are postseismic velocities averaged over 2007/2009-2015 for the CMONOC-II campaign GPS and Xidatan cGPS sites, respectively. The red error bars indicate the range within $70 \%$ confidence level based on Monte Carlo simulations (grayblack colored dots in subplot (b)) using 2D dislocation model. The purple dots with error bars are benchmark postseismic transients at JB51 and JB30. Red dots represent fault-parallel postseismic transients at the GPS sites in the first year after the 2001 event (December 2001-November 2002). Gray dots are fault-parallel postseismic transients (October, 2003October, 2004) that are approximated from InSAR line-of-sight (LOS) displacement (Track 362, Figure 10 in Ryder et al. (2011)) on the basis of dominant east-west directed horizontal deformation and negligible vertical deformation for a strike-slip faulting on an almost eastwest striking fault. Because InSAR LOS data are prone to some bias due to non-tectonic motion that is not easy to remove in the data processing, the asymmetry pattern is not as clear as that shown in both early post- and later post-Kokoxili GPS observations. 

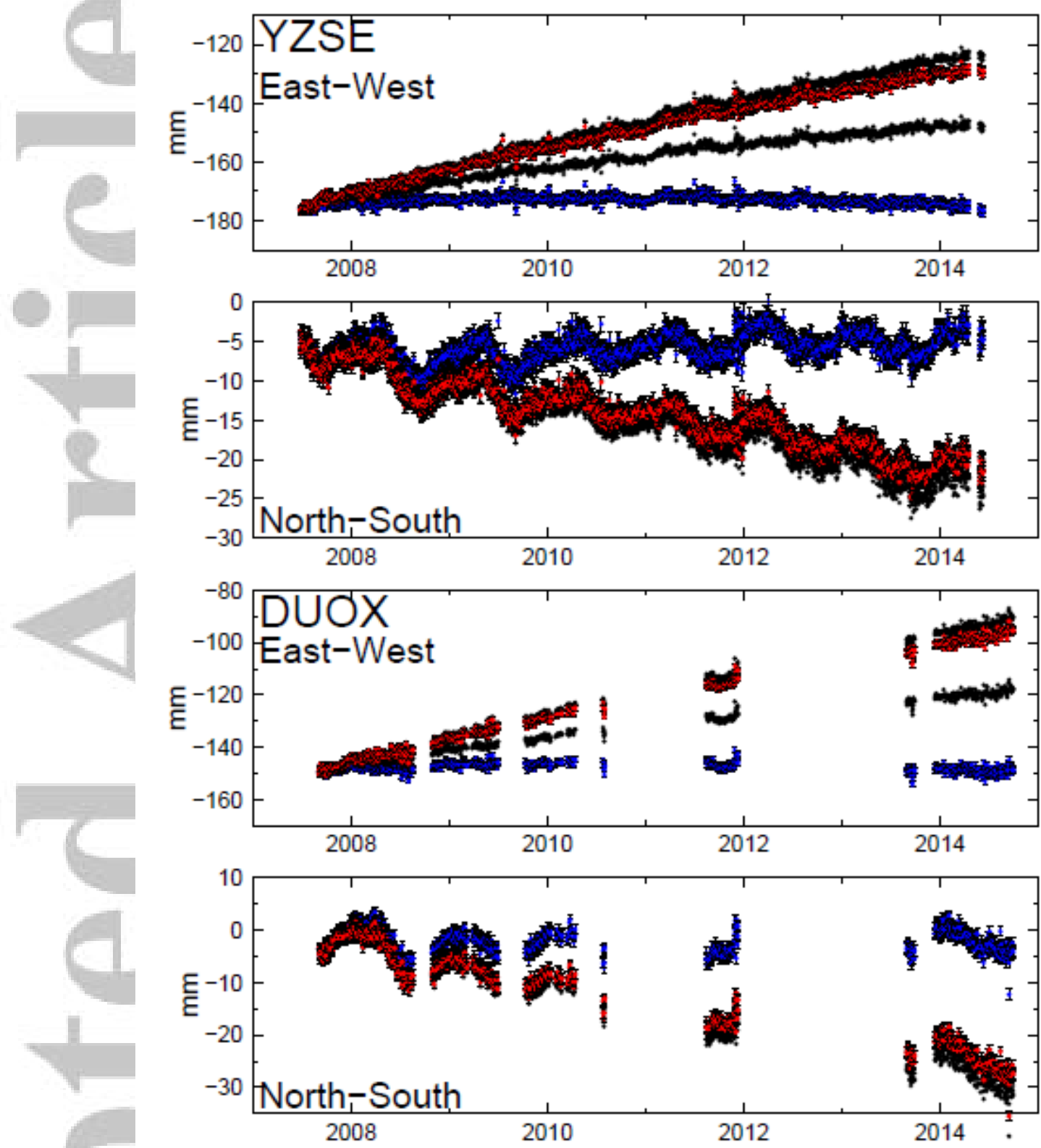

Figure 8. Postseismic GPS position time series at the Xidatan GPS sites minus steady motion based on nominally interseismic velocities derived from standard GPS time series analysis (blue dots) and the same velocities but with potential postseismic transients removed (red and black dots). Error bars are one-sigma formal error. The range bounded by black dots indicates the $70 \%$ confidence level. 


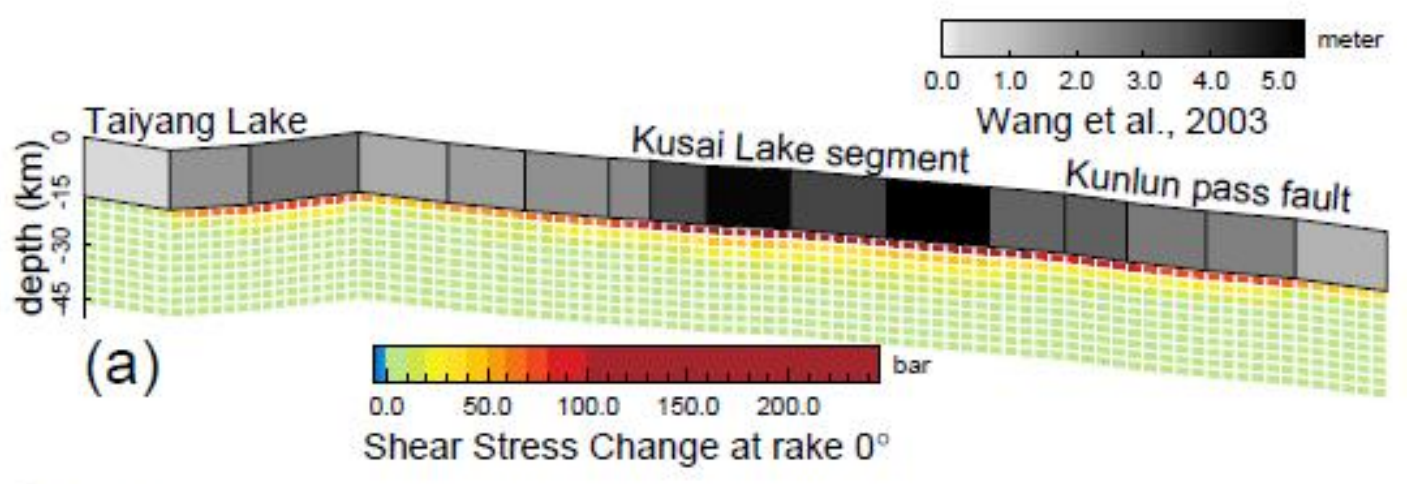

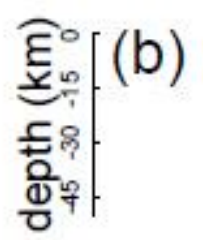

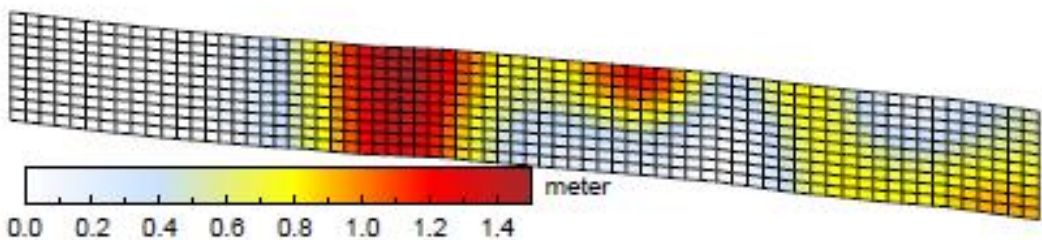

Kinematic Afterslip (Dec. 2001-Nov. 2002)

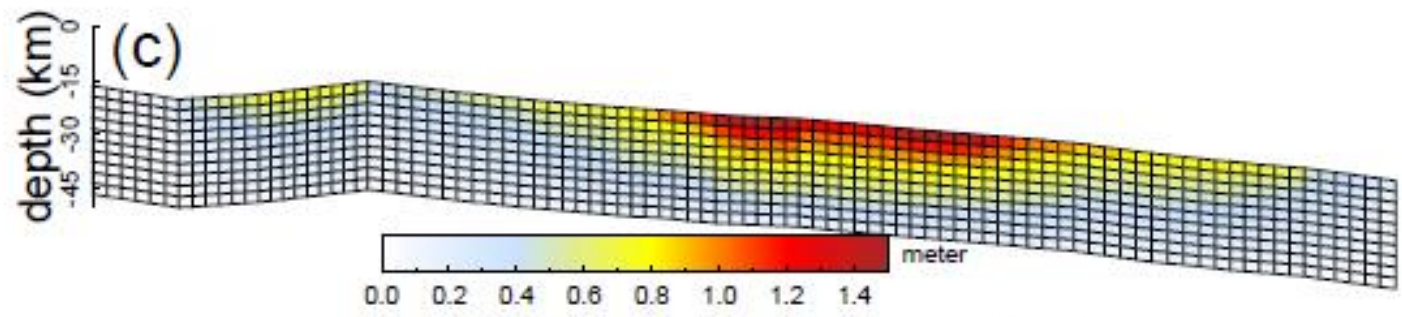

Frictionless Afterslip (Dec. 2001-Nov. 2002)

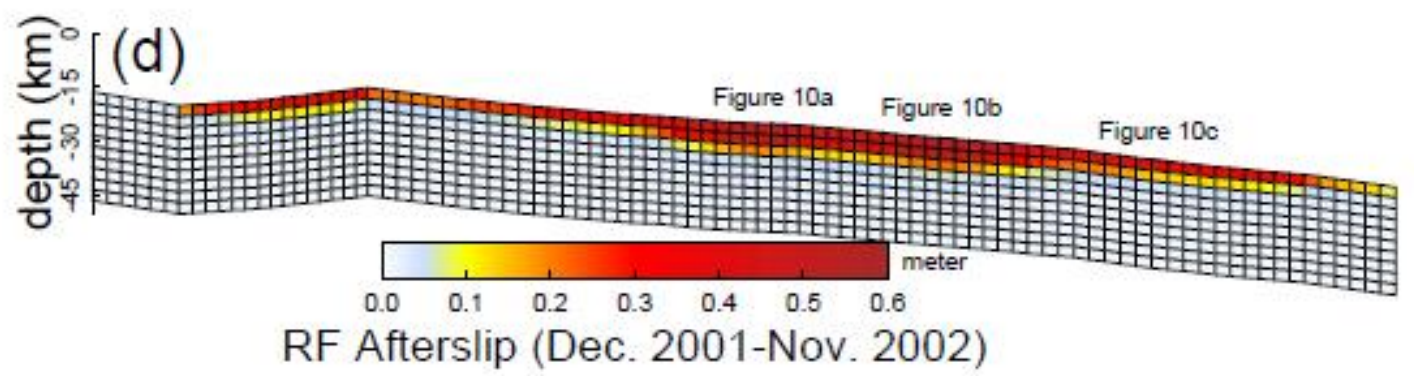

Figure 9. Distribution of deep afterslip. Shown in subplot (a) is the coseismic slip and associated coseismic shear stress change at rake $=0^{\circ}$ on the fault plane below. Shown in subplots (b), (c), and (d) are distribution of afterslip from kinematic inversion, stress-driven frictionless afterslip simulation, and rate-strengthening friction governed afterslip simulation, respectively. 

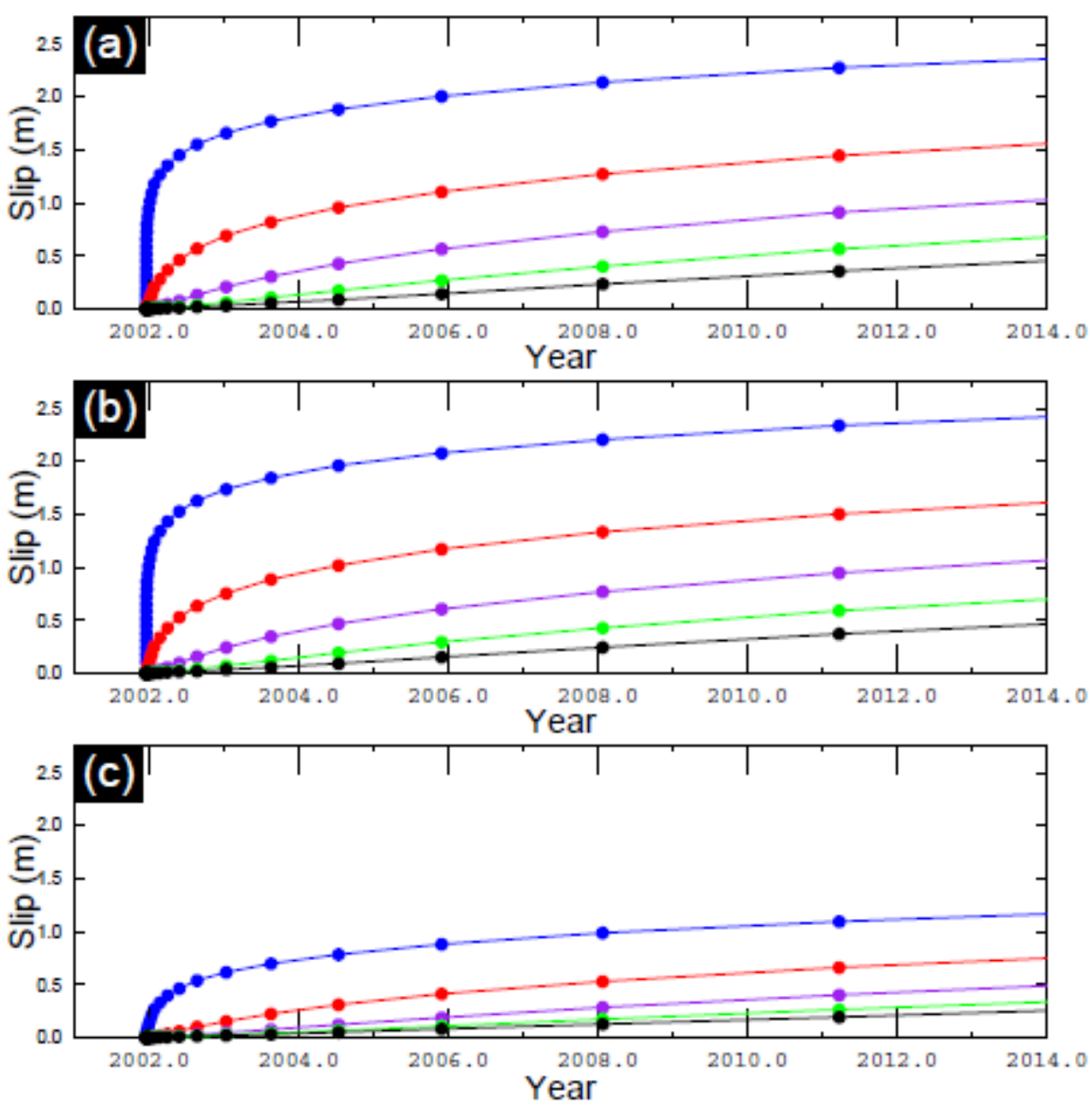

Figure 10. Temporal evolution of rate-strengthening friction governed afterslip on selected fault patches. Subplots (a), (b), and (c) show the results on the three columns (from west to east) of fault patches outlined by thick black lines in Figure $9 \mathrm{~d}$. In each subplot, the blue, red, purple, green, and black dots (lines) represent the temporal evolution of afterslip on fault patches at increasing depths (from 17-32 km). 


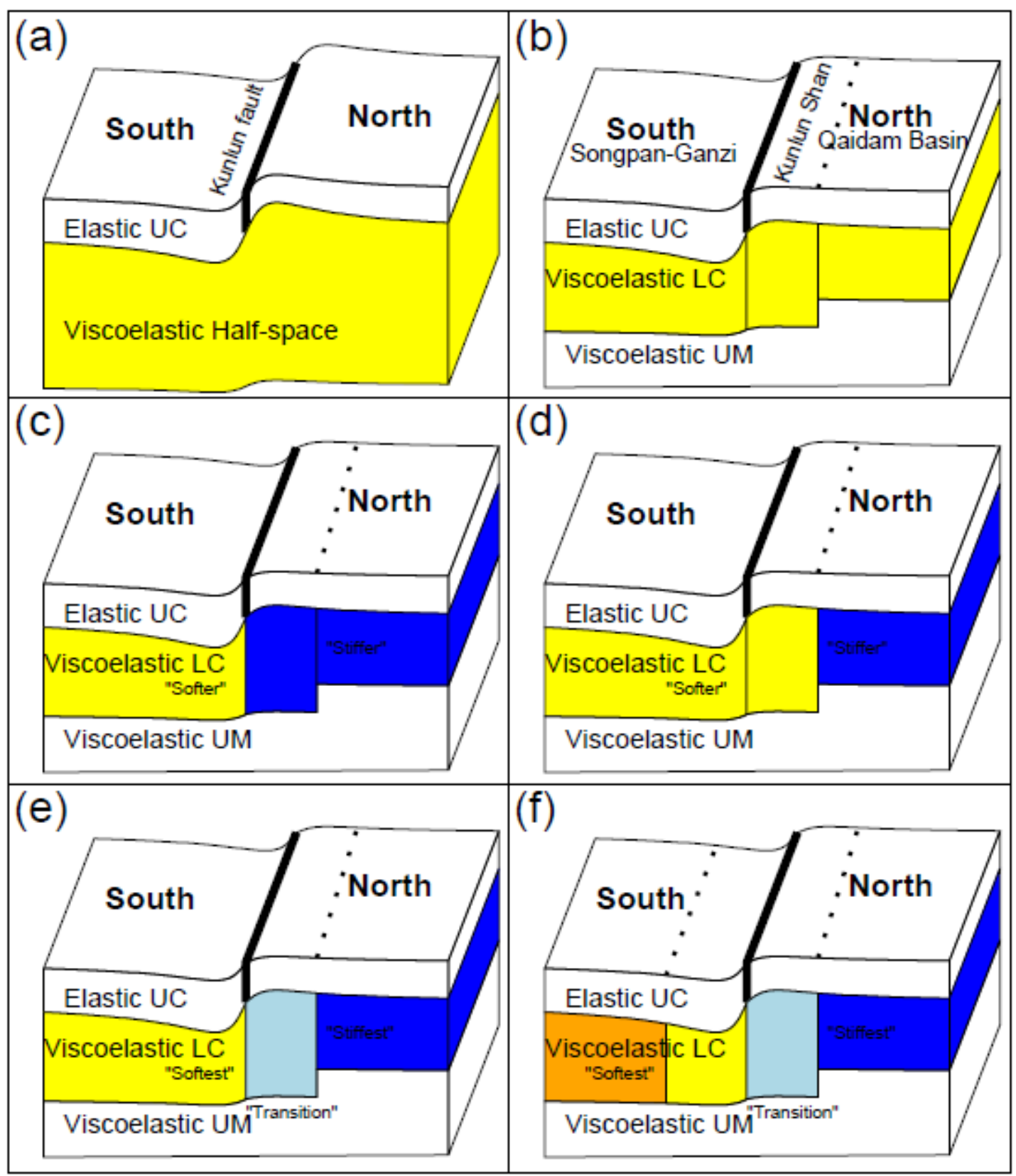

Figure 11. Schematic model geometry for (a) elastic UC overlying viscoelastic half-space (Model A), (b) laterally homogeneous viscoelastic LC sandwiched between elastic UC and viscoelastic UM (Model B), (c) laterally heterogeneous viscoelastic LC across the Kunlun fault sandwiched between elastic UC and viscoelastic UM (Model C); (d) the same as (c) but the heterogeneity boundary is along the southern margin of the Qaidam Basin (Model D); (e) a transition zone in the LC (marked by light blue rectangle) between the Kunlun fault and the southern margin of the Qaidam Basin (Model E); ( $f$ ) the same as (e) but with an additional heterogeneity boundary trending $S 82^{\circ} \mathrm{E}$ along the Jinsha River suture (dashed line in Model F). The dotted lines mark the positions of southern boundary of Qaidam Basin and Jinsha River suture, respectively. Also shown in model geometries (b)-(f) are the Moho depth variation across the southern margin of the Qaidam Basin. The sense of deformation is schematically illustrated by curve lines across the fault (thick black line in the UC) and its down-dip extension. Lower crustal heterogeneity is indicated by colored rectangles. 


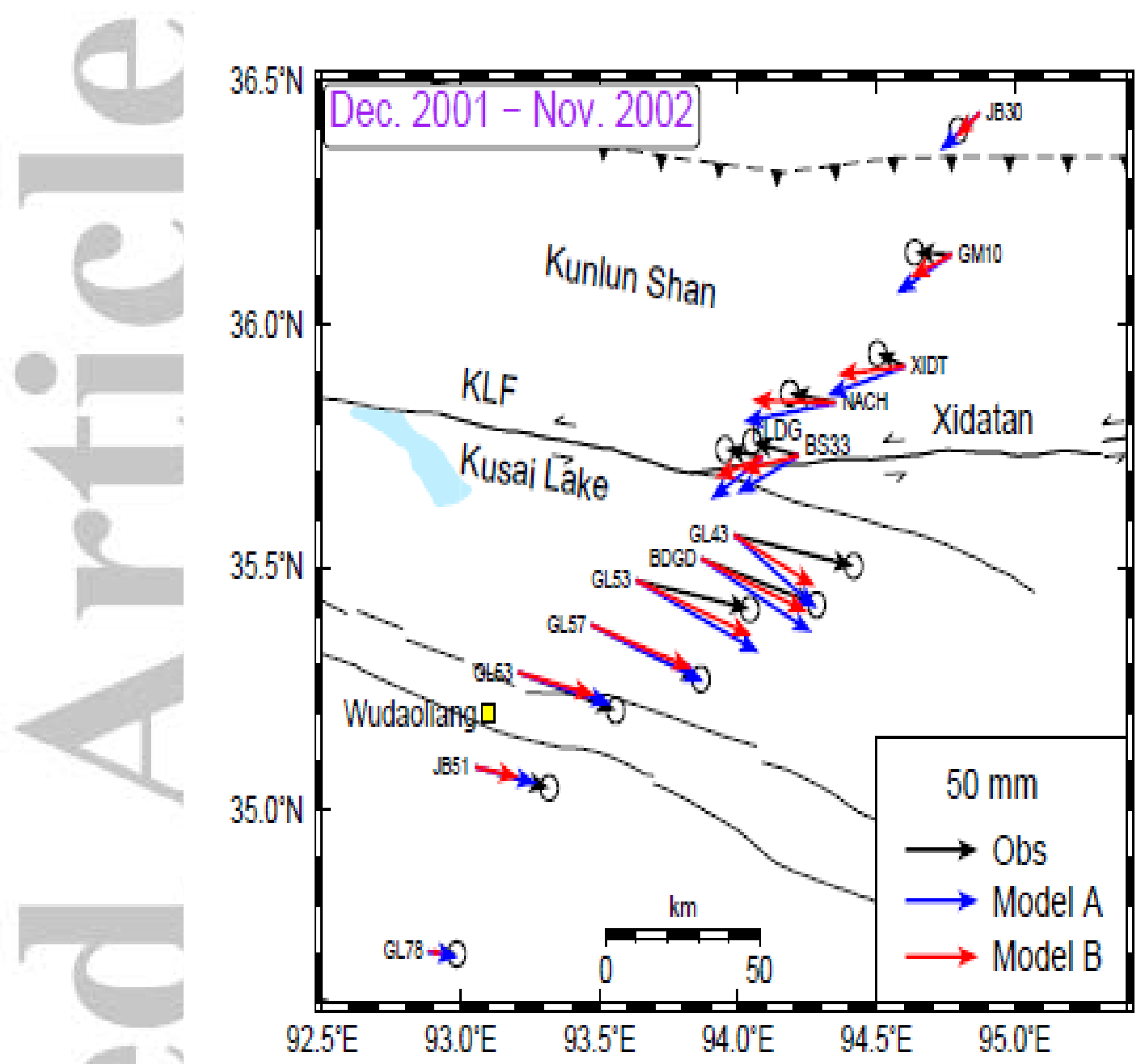

Figure 12. Map showing model predictions with respect to the 1-year cumulative displacement in the first year after the 2001 event. Black vectors are the observations with the contributions from afterslip removed. Blue and red vectors are model predictions from Model A and B. 


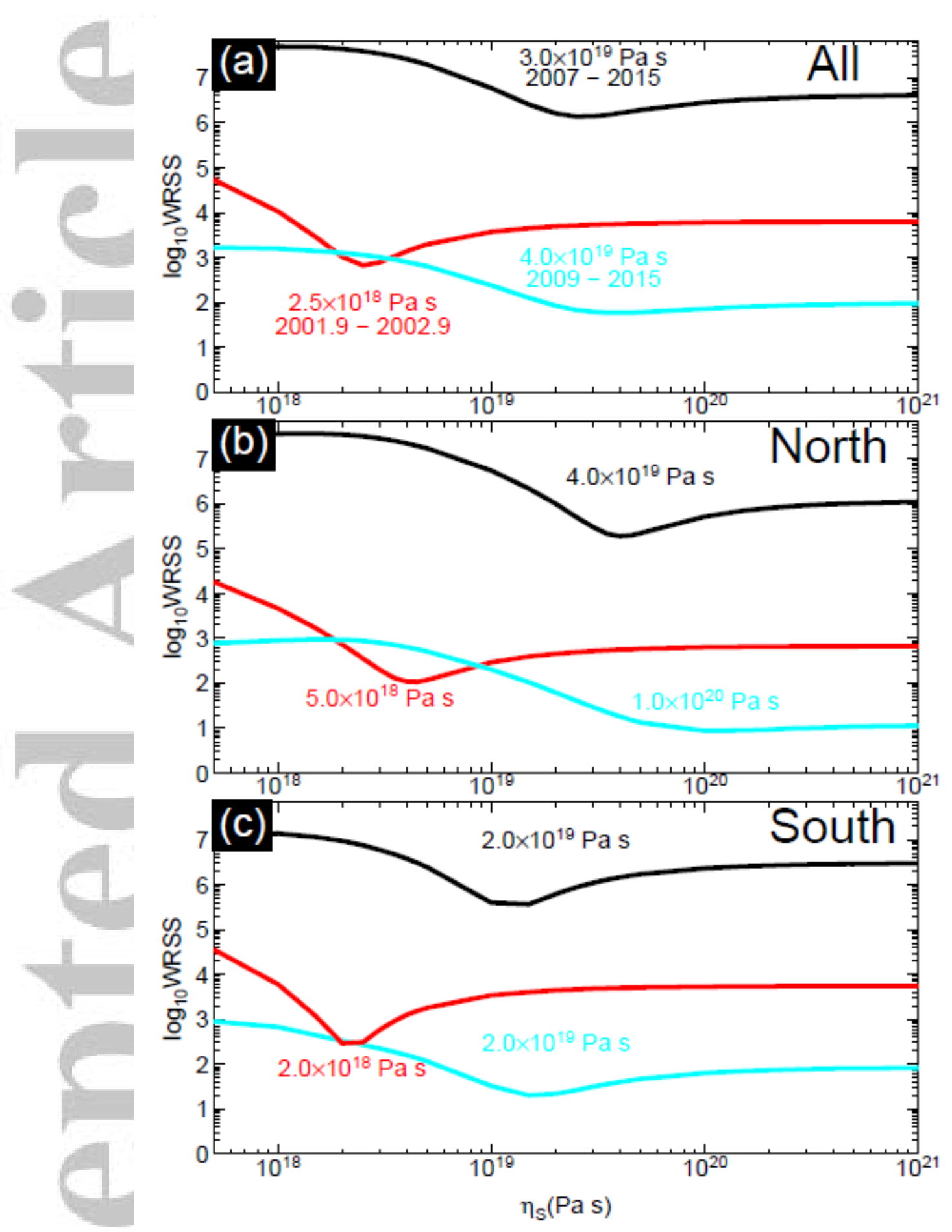

Figure 13. Weighted residual sum of squares as a function of viscosity of the lower crust (Model B). Shown in subplot (a), (b), and (c) are the results constrained by all the data, the data only in the northern side and in the southern side, respectively. The red, black, and cyan curves are for the 1-year cumulative displacement in the first year after the 2001 event, postseismic relaxation signals of the Xidatan GPS data (2007-2015), and post-Kokoxili CMONOC-II velocities (2009-2015), respectively. 


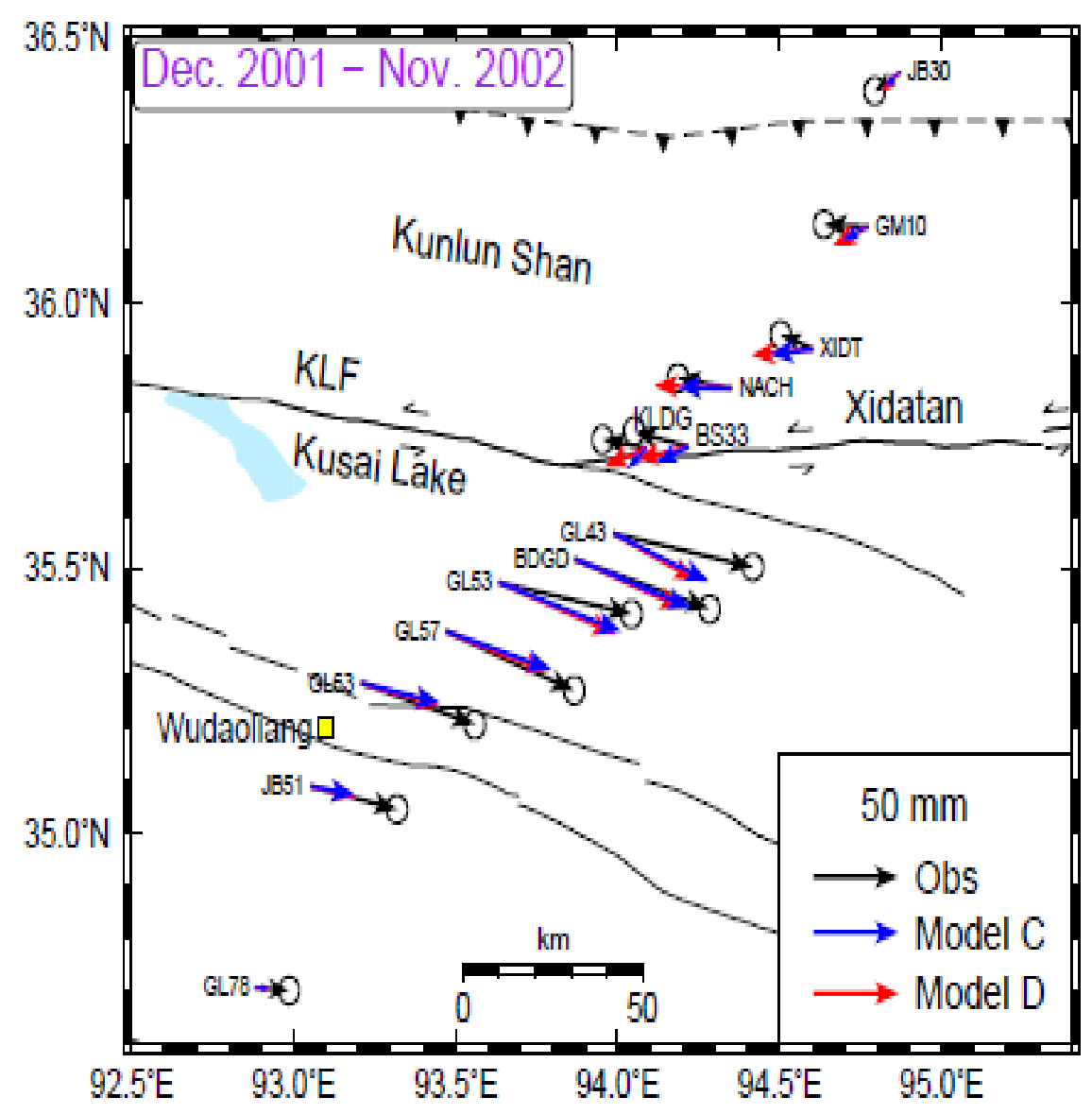

Figure 14. Similar to Figure 12, but with model predictions from Model C and D. 


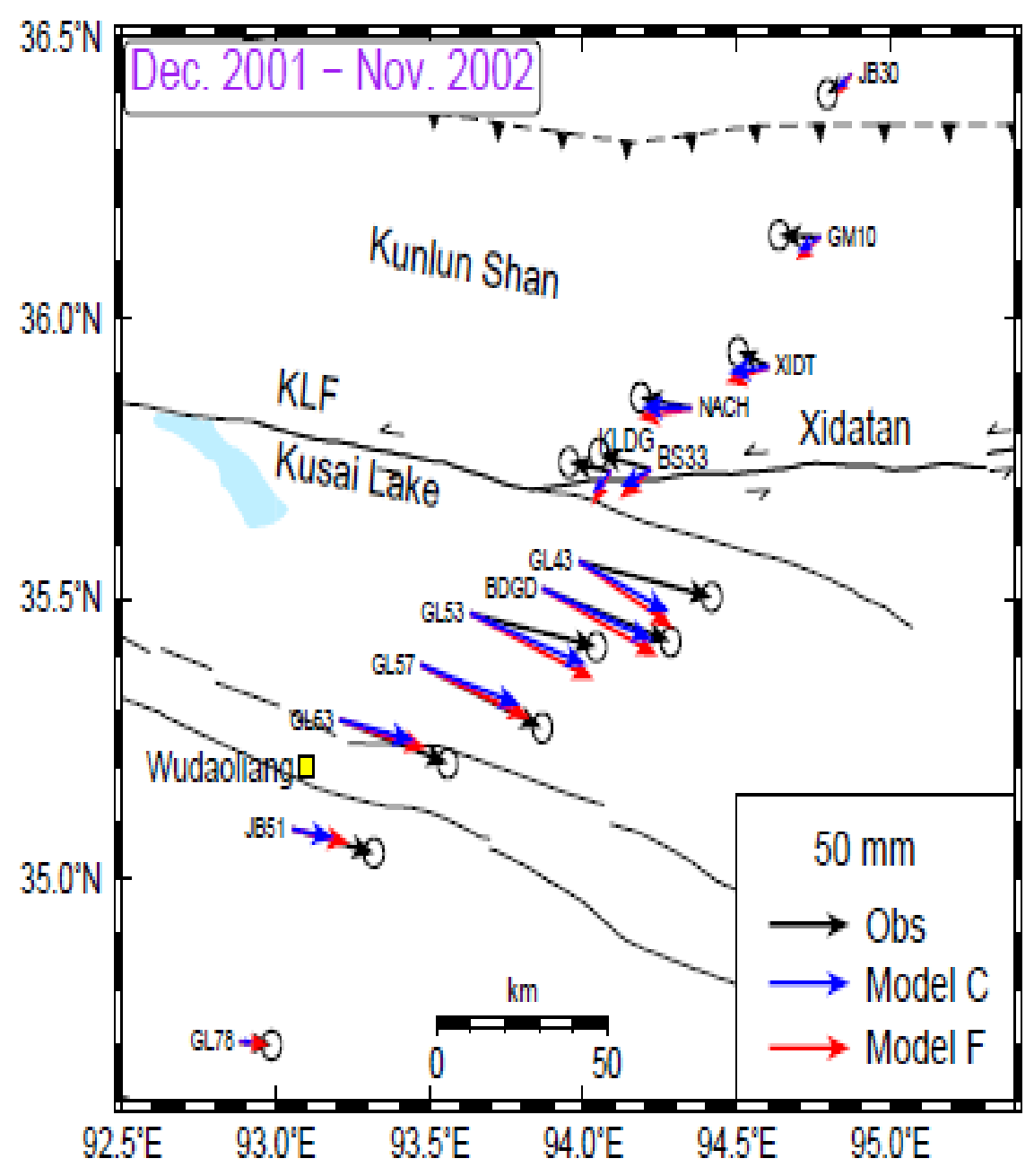

Figure 15. Similar to Figure 12, but with model predictions from Model C and F. 


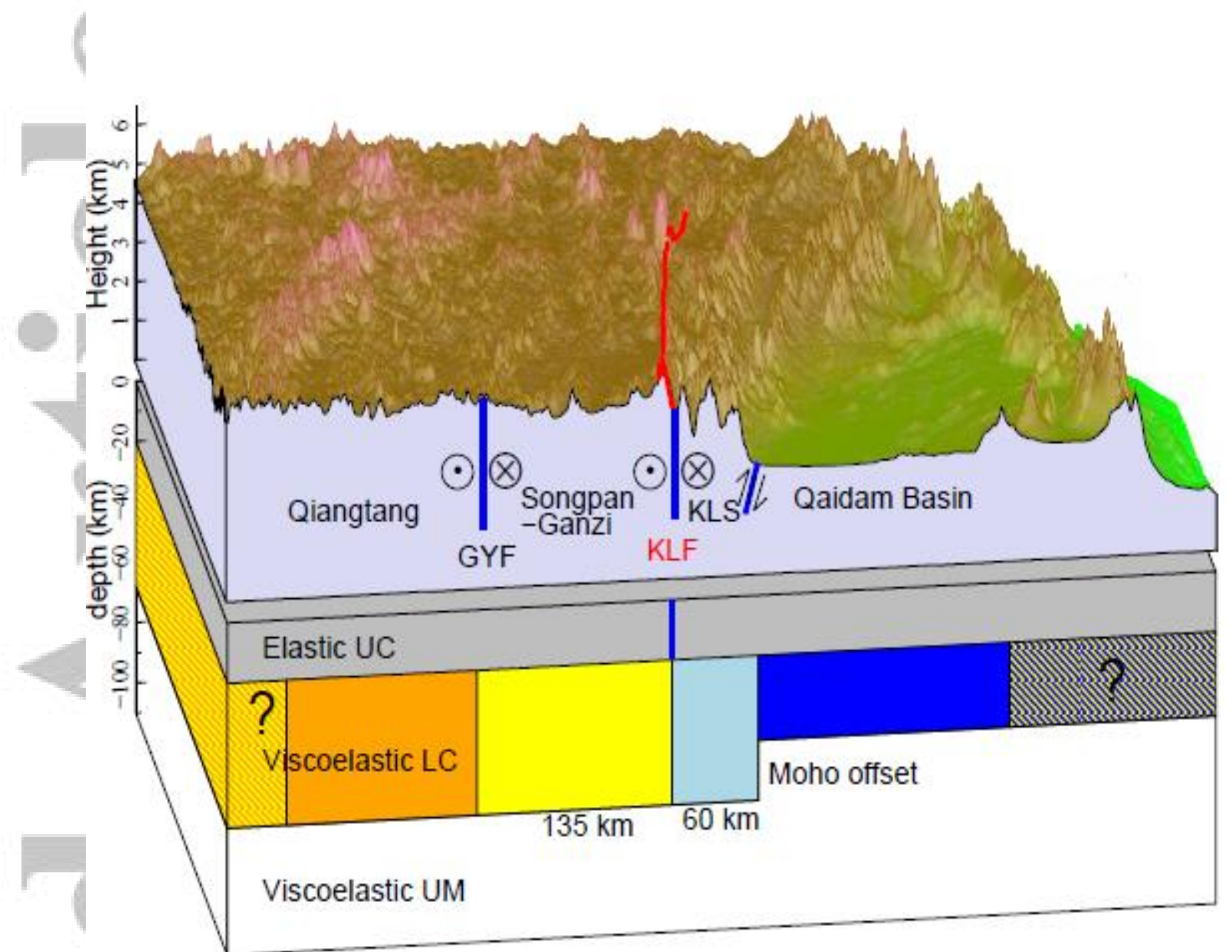

Figure 16. Schematic lithospheric structure of the northern Tibetan Plateau as inferred in this study. The topmost layer is the topography. The red line on the topography is the surface trace of the Kunlun fault. The three layers below represent the rheological structure inferred in this study (Figure 11f). Stepwise increase of the LC viscosity is schematically represented by the transition of warm colors to cool colors (orange, yellow, light blue, and blue). The question marks indicate that the viscosities of these regions are not well constrained because of insufficient far-field GPS data (e.g., rheological structure related to the underthrusting of the Indian plate beneath the Tibetan Plateau.). The vertical scale for the topography is exaggerated by a factor of ten. 